$\begin{array}{cl}\begin{array}{c}\text { Revue } \\ \text { de /histoire }\end{array} & \text { Revue de l'histoire des religions } \\ \text { des religions } & \begin{array}{l}3 \mid 2007 \\ \text { Varia }\end{array}\end{array}$

\title{
Hammam, nudité et ordre moral dans l'islam médiéval (I)
}

The Hammam, Nudity and Moral Order in Medieval Islam (I)

\section{Mohammed Hocine Benkheira}

\section{(2) OpenEdition}

\section{Journals}

Édition électronique

URL : http://journals.openedition.org/rhr/5303

DOI : $10.4000 /$ rhr.5303

ISSN : 2105-2573

Éditeur

Armand Colin

\section{Édition imprimée}

Date de publication : 1 septembre 2007

Pagination : 319-371

ISBN : 978-2200-92334-1

ISSN : 0035-1423

Référence électronique

Mohammed Hocine Benkheira, "Hammam, nudité et ordre moral dans l'islam médiéval (I) », Revue de I'histoire des religions [En ligne], 3 | 2007, mis en ligne le 01 septembre 2010, consulté le 19 avril 2019. URL : http://journals.openedition.org/rhr/5303 ; DOI : 10.4000/rhr.5303 


\section{Hammam, nudité et ordre moral dans l'islam médiéval (I)}

Avec le hammam, les oulémas ont été confrontés au problème épineux de la nudité physique. Tout en en restreignant la fréquentation pour les femmes, qui ne doivent s'y rendre que pour un motif légitime (menstrues, accouchement, maladie), on veille à la stricte ségrégation des sexes: baigneurs et baigneuses doivent ceindre un pagne. Cette doctrine, fixée dès le III/IX siècle, est martelée dans les siècles suivants par les juristes, toutes écoles confondues : c'est l'occasion pour eux de tenir un discours sur la sexualité des fidèles et de définir ce qu'est l'ordre moral conforme à la sharî́ca. Telles sont les conclusions de notre étude (en deux parties), fondée sur l'analyse de la littérature de traditions.

\section{The Hammam, Nudity and Moral Order in Medieval Islam (I)}

The Hammam confronted the ulemas with the vexed question of physical nakedness. While limiting access for women, who could go only for valid purposes (menstruation, birth, sickness), it was also necessary to ensure the sexes were strictly segregated: male and females bathers had to wear full-length loincloths. The doctrine, established by the $3^{\text {rd }} / 9^{\text {th }}$ century, was hammered home in later centuries by jurists of all schools, for it enabled them to speak out on believers' sexuality and to define moral order in keeping with the sharî $\hat{\imath}^{c}$. Such are the conclusions reached in this study (in two parts), which is grounded on the analysis of traditional literatures. 
Dans une précédente publication, nous avons établi que ce n'est pas en raison des rites d'ablution et de purification que les musulmans ont adopté le bain public, mais parce que, comme les Byzantins, les Romains et les Juifs, ils aimaient se baigner, par plaisir et aussi pour des raisons médicales. En outre, à certaines grandes occasions, comme le vendredi, pour la grande prière collective, mais aussi à la fin du jeûne de Ramadhân ou au cours du pèlerinage, la loi islamique recommande de prendre un bain ${ }^{1}$. On appelle ce bain ghusl, terme qui sert également à désigner la purification rituelle complète du corps, après des rapports sexuels, les menstrues et le retour de couches ${ }^{2}$. D'où une certaine confusion : par exemple, on a tendance à voir dans le bain du vendredi un rituel de purification, ce qu'il n'est pas en principe. Sa finalité exclusive est la propreté : le fidèle doit se présenter à la mosquée, pour ce rituel hebdomadaire majeur, sous sa meilleure apparence. Du même coup, on n'a pas été en mesure de voir que ce type de bain était la continuation de la culture du bain antique, mise au service du cérémonial islamique. Dans un premier temps, c'est sans aucun doute une des principales raisons de l'adoption rapide des thermes byzantins et de leur islamisation ${ }^{3}$.

\section{De ByZance À L'IsLam}

Tout en adoptant le bain public, les musulmans, surtout les plus sourcilleux en matière de morale, lui ont adressé de nombreuses

1. Le français désigne par le même mot «bain » à la fois l'acte de se laver et le lieu où l'on se lave (là où l'anglais en a trois : bath, bathhouse et bathing). Désormais, chaque fois que nous voudrons parler de ce dernier, nous utiliserons soit l'expression «bain public », soit le mot « hammâm », qui est passé dans la langue française. Il ne sera donc pas question des bains privés.

2. Le fait de traduire ghusl par «lotion »-c'est le choix, par exemple, de Georges H. Bousquet - empêche de voir que dans certains cas il s'agit d'un bain ! Voire même, il n'est pas défendu de s'immerger totalement dans une piscine pour procéder au ghusl de purification ; mais une aspersion de la totalité du corps y suffit. L'élément déterminant, c'est le statut rituel de l'eau.

3. Dans l'article auquel il était fait référence précédemment, nous avons également évoqué deux autres types de bain : celui qui suit une conversion et celui qui vise à combattre les effets du « mauvais œil ». 
critiques. Il est remarquable qu' on ne lui reprocha jamais explicitement ses origines byzantines, c'est-à-dire chrétiennes ; ses adversaires ne le condamneront pas pour cette raison, ce qui n'aurait pas été surprenant. Ainsi personne ne reproche aux baigneurs d'imiter les Byzantins $^{4}$, critique qui aurait été parfaitement légitime dans une perspective conservatrice ${ }^{5}$. Les juristes qui s'acharneront à poursuivre de leur vindicte les innovations blâmables $\left(b i d a^{c}\right)$, ne rangeront jamais le hammâm parmi celles-ci : ils dénonceront uniquement les comportements immoraux des baigneurs, sans jamais remettre en question le hammâm lui-même ${ }^{6}$.

Quelques uns des plus anciens textes religieux - qui datent du $\mathrm{III} / \mathrm{IX}$ siècle, mais sont la transcription d'un enseignement oral que l'on peut situer entre la fin du $\mathrm{I}^{\mathrm{er}} / \mathrm{VII}^{\mathrm{e}}$ siècle et le début du $\mathrm{II}^{\mathrm{e}} /$ VIII ${ }^{\mathrm{e}}$ siècle - témoignent sans ambiguïté que cette découverte ne laissa pas indifférents les hommes de religion, notamment les plus scrupuleux d'entre eux. Les premières traces d'une casuistique juridico-religieuse à propos du hammâm remontent à l'époque umayyade. Toutefois, les umayyades ne semblent pas avoir eu une attitude uniforme. Il y a tout lieu de penser que, à partir de 717, règne de ${ }^{\mathrm{c} U m a r} \mathrm{~b}$. ${ }^{\mathrm{c}} \mathrm{Abd}$ al-c $\mathrm{C}$ zîz, on assiste à un durcissement du pouvoir califal vis-à-vis du hammâm, à l'instigation de ce Calife particulièrement dévot. Plus généralement, le hammâm, à l'instar d'autres questions, va devenir un objet de controverse et de friction entre un groupe d'oulémas, hostiles par principe au confort matériel et à tout ce qui peut apparaître comme un luxe superflu, et l'aristocratie

4. Jusqu'au $\mathrm{IV} / \mathrm{X}^{\mathrm{e}}$ siècle, on continue parfois à parler de hammâm rûmî, c'est-à-dire byzantin (Encyclopédie de l'Islam, $2^{\mathrm{e}}$ édition, article hammâm).

5. Alors que les traditions prophétiques qui condamnent l'imitation des chrétiens et des juifs (voir à ce sujet Georges Vajda, «Juifs et musulmans selon le hadîth », Journal Asiatique, CCXXIX, 1937, 57-127) sont nombreuses à propos de toutes sortes de sujets, nous n'en avons jamais rencontré une qui ait pour objet le hammâm. Même Ibn al-Hâjj (m. 737/1 336) dont le traité ne manque pas d'épingler tous les usages empruntés aux chrétiens et aux juifs (par exemple, Madhal, Beyrouth, 1995, I, 267 et sq.) n'établit jamais de lien entre la critique du hammâm et ses origines byzantines.

6. Dans sa rapide revue des traités sur les bidac, Maribel Fierro, "The treatises against innovations (kutub al-bidac)", Der Islam, XXIX, 1992, n² 2, 204-43, n'évoque à aucun moment le hammâm. 
arabe, qui n'hésite pas à imiter les grandes civilisations du moment (Byzance, Iran sassanide). Ce groupe d'oulémas est le noyau qui va donner naissance d'abord au courant des ahl al-hadît, adversaires des formes de pensée rationalistes (mu'tazilites, philosophes), ensuite plus tard aux ahl al-sunna, appelés à devenir le courant religieux majoritaire.

Le débat au sujet du hammâm a évolué mais n'a jamais vraiment pris fin - puisque même de nos jours, il existe des adversaires du hammâm ${ }^{7}$. D'abord franchement hostiles au hammâm, pour plusieurs raisons dont certaines ont été étudiées précédemment, les oulémas vont faire preuve d'une certaine souplesse et nuancer leur position à son égard durant la première moitié du $\mathrm{III}^{\mathrm{e}}$ siècle: tout en demeurant opposés à sa fréquentation par les femmes, ils ne condamnent plus les hommes qui s'y rendent. Ils vont même jusqu'à admettre pour la première fois que les femmes peuvent s'y rendre à des conditions précises, c'est-à-dire pour des raisons médicales, après un accouchement ou des menstrues. Dès cette même époque, on enregistre des traditions dans ce sens dans les collections canoniques sunnites et, au siècle suivant, dans les collections imâmites.

Les juristes n'ont jamais contesté l'idée de bain thérapeutique ; car elle était admise de tous depuis longtemps ${ }^{8}$. Après le III $^{\mathrm{e}}$ siècle,

7. Cf. Omar Carlier, « Les enjeux sociaux du corps. Le hammam maghrébin ( $\mathrm{XIX}^{\mathrm{e}}-\mathrm{XX}^{\mathrm{e}}$ siècles), lieu pérenne, menacé ou recréé », Annales H.S.S., tome LV, 2000, $\mathrm{n}^{\circ}$ 6, 1303-33.

8. Sur les rapports entre bain et médecine dans l'Antiquité, voir Actes du colloque organisé à Paris par le CNRS et la Fondation Singer-Polignac (25-27 nov. 1992), L'eau, la santé et la maladie dans le monde grec, édités par René Ginouvès, Anne-Marie Guimier-Sorbets, Jacques Jouanna et Louis Villard, École française d'Athènes, in Bulletin de Correspondance hellénique, supplément XXVIII, 1994, 25-40, 41-60, 109-19, etc., et Fikret Yegül, Baths and bathing in classical Antiquity, Cambridge, 1992, 352-5. Il n'existe à ce sujet aucune synthèse pour ce qui concerne le monde islamique : voir Râzî, Guide du médecin nomade, Sindbad, 1980, 71 ; Hosam Elkhadem, Le Taqwîm al-Sihha d'Ibn Butlân : un traité médical du XI siècle, Louvain : Peeters, 1990, 275-6 ; Abû Sahl cÎsâ b. Yahyâ al-Mâsîhî, Kitâb al-mî'a fì al-tibb, édition et introduction Floréal Sanagustin, Damas, IFEAD, 2000, I, 106, 176, 207-10 ; Masîh b. Hakam al-Dimashqî, al-Risâla al-hârûniyya, texte établi, traduit et annoté par Suzanne Gigandet, Damas, IFEAD, 2002, 122-4 ; Salâh al-dîn b. Yûsuf alKahhâl al-Hamawî, Nûr al-c ayn wa jâmic al-funûn, édition Wafâ'î et Qalcajî, 
on continua à jeter l'opprobre sur le hammâm dans certains milieux restreints, comme le courant hanbalite ou dans des cercles soufis 9 . Entre-temps, après l'imposition du port du pagne notamment et la spécialisation de certaines heures pour les femmes, le hammâm a été acclimaté à la morale de la nouvelle religion. Quant aux hommes de religion, beaucoup d'entre eux mirent relativement fin à leurs récriminations contre le hammâm et ses amateurs, à telle enseigne que vers le $\mathrm{IX}^{\mathrm{e}} / \mathrm{XV}^{\mathrm{e}}$ siècle, on pouvait rencontrer au Maghreb des bains publics consacrés biens de mainmorte (hubus) au profit d'hommes de religion réputés ${ }^{10}$.

Le bain public a traversé plusieurs civilisations, au prix de modifications conformes à l'esprit de ceux qui l'ont adopté. Les musulmans lui ont fait subir des transformations qui sont dans la continuité de celles introduites par les chrétiens avant eux : pour l'essentiel, elles ont trait à la nudité du corps. Ils n'ont pas eu ainsi

Riyâdh, 1987, 275, 276, 289 et 296. Les idées médicales ont du reste pénétré la littérature religieuse comme l'attestent les ouvrages qui relèvent du genre «médecine prophétique » (tibb nabawî). Plus largement les préceptes des médecins sont repris dans des manuels de toute sorte comme Al-baraka fí fadhl al-sacy wa-l-haraka (La Mecque, 1993, 279) de l'Egyptien Abû cAbd Allâh Muhammad b. ' Abd al-Rahmân b. ' Umar al-Wasâbî al-Habîshî (m. 782/1381).

9. Comme en témoignent les œuvres de Abû Tâlib al-Makkî (m. 386/996) et Ghazzâlî (m. 505/1111).

10. Vincent Lagardère, Histoire et société en Occident musulman, Madrid, coll. de La Casa de Velázquez, 1995, 134, n 90 et 227-8, n 6. Mais le phénomène est manifeste bien avant cette époque en Andalousie et au Maghreb : Lagardère, op. cit., 271, n 209 ; Rachel Arié, L'Espagne musulmane au temps des Nasrides (1232-1492), De Boccard., 1973, 295. Au IV'/ $X^{\mathrm{e}}$ siècle, Muhammad b. Ishâq, qui était le grand cadi de Cordoue, achète un hammâm. À la même époque, Yahyâ b. Tammâm, un juriste de Ceuta, fait de même (Lagardère, op. cit., $350, \mathrm{n}^{\circ} 255$ et 256 , de même que $443, \mathrm{n}^{\circ} 88$ ). Au siècle suivant, un cadi de Cordoue fit construire un hammâm pour son profit personnel (Lagardère, op. cit., $454, \mathrm{n}^{\circ}$ 134). Par la suite, la chose devient banale, comme dans Le Caire du $\mathrm{XVIII}^{\mathrm{e}}$ siècle (André Raymond, Artisans et commerçants du Caire au XVIII siècle, Damas, IFEAD., 1974, II, 429). Le revenu tiré de la fréquentation du hammâm par les clients sert à l'entretien de celui au profit de qui le hubus a été institué : si à partir d'une certaine époque, des hommes de religion, par ailleurs scrupuleux sur le plan religieux, acceptent de vivre ainsi, c'est qu'ils considèrent que l'argent que procure le hammâm n'est entaché d'aucune faute sur le plan moral (voir Mohammed H. Benkheira, " "La maison de Satan". Le hammâm en débat dans l'islam médiéval », Revue de l'histoire des religions, CCXX, 2003, n 4, 416-7). 
à combattre la mixité des bains, la bataille ayant déjà été menée par les Byzantins. Toutefois, d'après quelques textes, les bassins où l'on pouvait s'immerger à plusieurs se sont perpétués encore quelque temps, avant de disparaître totalement. Deux problèmes vont préoccuper en particulier les oulémas - ascètes, juristes et moralistes. Le premier a trait à la chasteté des femmes mariées car il n'est jamais question des jeunes filles. La sortie pour se rendre au bain ne peutelle pas constituer une occasion d'adultère ? Le fait qu'à l'intérieur du hammâm les femmes soient exclusivement entre elles ne constitue en rien une garantie contre la licence sexuelle. En effet, on y rencontre des entremetteuses, qui peuvent servir de « courrier » entre les femmes et leurs amants. Par ailleurs, le comportement de certaines femmes, les plus dévergondées, qui se promènent entièrement nues dans la salle chaude, peut influer sur celui des femmes pudiques. C'est pour cela qu'à l'égard des femmes, l'attitude demeure très hésitante. Les tentatives d'interdire définitivement la fréquentation du hammâm aux femmes n'ont pu cependant aboutir. Les juristes ont été obligés d'admettre des cas de dispense, notamment pour raisons de santé ou pour le retour de couches. Plus tard, avec une certaine réticence, ils ajouteront la fin de la période menstruelle. Certains assortiront cette possibilité de l'obligation pour la femme d'être accompagnée, par quelqu'un qui pourrait veiller sur sa chasteté. C'est pour cela qu'il n'est pas surprenant de constater que la salle de bains moderne, intégrée à la demeure familiale, a été adoptée avec célérité car elle correspond mieux à l'esprit puritain de certains courants islamiques. Le second problème concerne exclusivement les hommes. Dans ce cas, le danger dont il faut se prémunir est l'homosexualité.

Les règles définies par les juristes pour la fréquentation du hammâm ont mis du temps à s'imposer. Dans un premier temps, alors qu'ils sont totalement hostiles à sa fréquentation, les juristes sont en total décalage par rapport à la majorité de leurs contemporains, qui le fréquentent régulièrement. Se rendant compte sans doute de l'importance de l'écart, ils sont obligés de nuancer leur position. Ainsi il ne faut pas croire que les règles posées par les juristes sont immédiatement entérinées par les autorités de l'époque ainsi que par les fidèles. Nous avons une disjonction nette entre les deux processus : 
alors que musulmans, dont les classes dirigeantes, et non musulmans continuent de fréquenter le bain public comme auparavant, les juristes tentent de définir la position de la loi islamique vis-à-vis de ce lieu. La grande masse des fidèles n'y adhérera que dans la mesure où elle ne jettera pas l'opprobre sur le hammâm mais dans la mesure aussi où la grande masse des fidèles sera elle-même pénétrée du souci de faire coïncider son comportement avec la définition proposée par les juristes.

Entre la fin du second et le milieu du troisième siècles, le jugement des hommes de religion a évolué favorablement au hammâm, même s'ils ne donnent pas une approbation totale à sa fréquentation et se maintiennent sur une certaine réserve. Cet apaisement dans le débat est inséparable d'une autre évolution importante : en même temps que la casuistique sur le hammâm va se simplifier, un certain nombre de questions tombant en désuétude, le problème de la police sexuelle va prendre de l'ampleur et dominer de manière quasi-exclusive. Le hammâm deviendra ainsi un des objets qui aideront à préciser les contours de la morale sexuelle en cours de formation, notamment en relation avec deux notions majeures - les parties honteuses $\left({ }^{c} a w r a\right)^{11}$ et la pudeur $\left(\text { hay } \hat{a}^{\prime}\right)^{12}$ - ; cette dernière sera simultanément définie comme une composante essentielle de la foi.

11. Au sens premier, ${ }^{c} a w r a$ désigne « les parties honteuses » (il y a une parenté entre ${ }^{c} \hat{a} r$, honte, et ${ }^{c} a w r a$ ), «les parties génitales », «le bas-ventre », « les organes de la génération» de l'homme comme de la femme. Pourtant la casuistique juridique a donné au mot une extension nouvelle. Dans la formule «la femme est ${ }^{c} a w r a »$, il s'agit de dire que chez la femme les parties honteuses absorbent sur le plan légal la totalité de son corps, voire même sa voix ou le tintement des bijoux qu'elle peut porter. C'est pour cela que l'on peut traduire aussi ce mot par «nudité ». Sur cette notion voir Mohammed H. Benkheira, L'amour de la Loi. Essai sur la normativité de l'islâm, PUF, 1997, index, s.v.

12. À partir de ce moment, la formulation du problème va être fixée : on va parler de adâb duhûl al-hammâm, "règles de la fréquentation du bain public ». C'est après avoir achevé la rédaction de cet article que Jacqueline Sublet a attiré mon attention sur un manuscrit dont la Section arabe de l'IRHT (CNRS, Paris) possède le microfilm et qui est intitulé Kitâb al-ilmâm bi-adâb duhûl al-hammâm wa mâ yatacallaq bihi min al-ahkâm, dont l'auteur est le shâficîte Abû al-Mahâsin al-Husaynî Muhammad b. 'Alî Shams al-dîn alDimashqî (715-765/1314-1365). La copie, dont certains folios sont illisibles, date de 810/1408; elle provient de la Bibliothèque Köprülü à Istanbul $\left(n^{\circ} 1214\right)$. Un rapide survol du manuscrit montre qu'il n'apporte rien de neuf. 
Aujourd'hui, dans la plupart des pays musulmans, le hammâm fait partie des lieux dont presque personne ne conteste la nécessité. À certaines époques quand les oulémas durcissent leurs attitudes envers la vie sociale, jugeant qu'elle est envahie par le relâchement des mœurs, voire le libertinage, et où certains courants radicaux tentent d'imposer leur puritanisme à l'ensemble de la société, il est sinon contesté, du moins cherche-t-on à exercer sur sa fréquentation un contrôle plus étroit et une surveillance plus pointilleuse. Il s'agit là de périodes de crise morale et religieuse. En dehors de ces moments exceptionnels, le hammâm s'intègre parfaitement au paysage social. C'est pour cela qu'à quelques exceptions près, le hammâm semble toujours avoir fait partie des structures urbaines en terre d'islâm : au Moyen-Âge, même les campagnes n'en étaient pas dépourvues ${ }^{13}$. Toutefois, partout où l'occidentalisation du mode de vie progresse, son existence est menacée et il est en voie d'être supplanté par la salle de bains ou la douche. Seule résiste la source d'eau chaude car elle a des fonctions thérapeutiques ${ }^{14}$. Il est difficile de ne pas y voir un élément essentiel de la civilisation islamique, presque au même titre que la mosquée. Pour la plupart des musulmans, en tout cas dans les pays où il est (ou était) répandu, il constitue (ou a constitué) un équipement essentiel, peu discutable sur le plan moral et religieux tant que deux règles essentielles y sont (ou étaient) respectées plus ou moins scrupuleusement.

La première règle est que la fréquentation du hammâm doit demeurer « unisexuelle» : les femmes ne doivent y être qu'entre elles, de même que les hommes. Les deux sexes ne doivent jamais s'y retrouver ensemble : on doit respecter une stricte ségrégation des sexes. Telles heures dans la journée ou tels jours dans la semaine sont réservés aux femmes et tels autres aux hommes ${ }^{15}$. Cette règle ne souffre aucune exception. Au moment où le bain est réservé à la clientèle féminine, le

13. Arié, op. cit., 394.

14. Selon Martin Dow, The islamic baths of Palestine, Oxford, 1996, xiii, le hammâm est sur le déclin au Moyen Orient depuis le XIX siècle.

15. Au Maghreb, par exemple, l'après-midi (entre 13h et $17 \mathrm{~h}$ ) est réservé aux femmes. C'était déjà le cas dans l'Occident musulman au Moyen Âge (Evariste Lévi-Provençal, Histoire de l'Espagne musulmane, Maisonneuve et Larose, 1999 [1950], III, 430 ; Arié, Idem). Au début du XXe siècle, à Damas, les bains publics étaient réservés aux femmes au commencement de l'après-midi 
personnel est également féminin : il ne peut être question d'y admettre des employés masculins, même efféminés. Le corps de la femme est tabou dans sa totalité ; seul son époux (ou son maître, pour les esclaves) a le droit de le contempler. Il n'y a guère longtemps, même le visage devait être voilé devant les " étrangers », y compris les parents au degré non prohibé. Dans ce système, les jeunes garçons, qui ont un statut ambigu, constituent une exception. En effet, ils peuvent aller au bain avec la mère ou le père, indifféremment, jusqu'à ce que l'on estime qu'ils ont cessé d'être en âge de fréquenter le bain avec les femmes. Quand la maman veut continuer à emmener son fils au bain le jour des femmes, la tenancière ou les autres femmes peuvent lui faire observer qu'il est devenu un homme. Ce qu'il y a de remarquable c'est que seuls les jeunes garçons vivent une telle ambiguïté : les petites filles ne vont jamais au bain avec les hommes. Il y a une étrange dissymétrie entre jeunes garçons et petites filles ${ }^{16}$.

jusqu'à l'appel pour la dernière prière de la journée. À la même époque, en Palestine, alors que la journée était entièrement réservée aux femmes et la nuit aux hommes, à Gaza, le bain était réservé aux hommes le matin jusque vers $11 \mathrm{~h}$. À Jérusalem existait un bain exclusivement réservé à la clientèle masculine (Dow, op. cit., 2). À Sancâ', les bains étaient réservés aux hommes pendant quatre jours et aux femmes pendant trois jours (Robert Serjeant et Ronald Lewock, eds, San' $\hat{a}^{\prime}:$ an Arabian Islamic City, Londres, 1983, 516 ${ }^{\mathrm{b}}$ ). La ségrégation sexuelle du temps, apparue sans doute la première fois dans la Grèce ancienne (René Ginouvès, Balaneutikè. Recherches sur le bain dans l'Antiquité grecque, De Boccard, 1962, 220-4), a été rétablie par certains empereurs romains, puis systématisée, sous l'influence des Pères de l'Église, par les Byzantins (Louis Bréhier, La civilisation byzantine, A. Michel, coll. L'évolution de l'Humanité, 1950, 13), qui l'ont transmise aux musulmans. Ces derniers ne l'ont pas empruntée à Byzance, ils l'ont trouvé déjà là quand ils sont arrivés en Syrie, en Palestine et en Égypte. Il est significatif que jamais aucun texte ancien, parmi ceux qui seront examinés plus loin, ne fasse référence à la mixité des bains : on reproche à certaines femmes de fréquenter les bains publics, mais jamais elles ne sont accusées d'y aller en même temps que les hommes. Si tel avait été le cas, les adversaires du hammâm n'auraient pas manqué de le relever. Dans l'Europe occidentale, vers la fin du Moyen-Âge, il n'en fut pas de même : la royauté dut intervenir pour séparer les sexes, comme le 11 février 1399 à Paris, ou grâce à l'ordonnance du 14 avril 1410 de Dijon (Dominique Laty, Histoire des bains, PUF, coll. Que sais-je ?, 1996, 46). Cette mixité porta préjudice à la réputation des bains publics et contribua à leur déclin dans cette ancienne partie de l'Empire romain.

16. Abdelwahab Bouhdiba, qui signale cette dissymétrie, n'en propose aucune interprétation (La sexualité en islam, PUF, 1975, 206-10). 
La seconde règle qui s'impose dans le hammâm musulman est double : de même que l'on doit cacher ses parties grâce à un pagne, on doit éviter absolument de porter le regard sur la nudité d'autrui. Ainsi on ne doit pas y adopter des attitudes indécentes. Si la première règle est une invention des Byzantins, la seconde est le fait des juristes musulmans. La première, qui coïncide avec la bipartition fondamentale qui structure la totalité de l'univers, n'est jamais transgressée ; la seconde l'est souvent - c'est pour cela qu'elle doit être constamment rappelée aux clients soit par d'autres clients, prudes ou pieux, soit par les employés et les patrons.

\section{LES IMAGES DANS LES BAINS PUBLICS}

Henri Lammens a soutenu, s'appuyant sans aucun doute sur des sources tardives, que l'interdiction de fréquenter le hammâm était motivée non par le souci de la pudeur mais par la présence dans les bains de cette époque, y compris sous les Abbâsides, de peintures murales. ${ }^{17}$ Durant au moins les trois premiers siècles de l'Hégire, la littérature religieuse ne fait état d'aucune critique liée à ce fait, adressée aux bains. Si l'attitude défiante de certains oulémas envers le hammâm avait trouvé son origine dans la présence d'images dans ce lieu si controversé, pourquoi les compilations de traditions n'en font-elles pas état, alors même qu'elles contiennent de nombreux textes qui condamnent explicitement toute représentation figurée de la vie animale ? Un fait ne manque pas d'intriguer: pas une seule tradition prophétique, parmi celles qui mettent en garde les musulmans contre la fréquentation des bains, ne fait référence aux images ${ }^{18}$. Ghazzâlî (m. 505/1111), qui est un des premiers juristes à formuler ce reproche, n'appuie sa dénonciation sur aucune tradition. Un autre fait est intéressant. Il évoque dans deux endroits différents le hammâm dans son traité : la question des images est traitée dans « Le livre du

17. Études sur le siècle des Omeyyades, Beyrouth, 1930, 372.

18. Ce n'est que dans les traités juridiques de la période classique que le problème des images est traité en relation avec les bains publics (Daan van Reenen, « The Bilderverbot, a new survey », Der Islam, 1990, LXVII, Heft 1, 54). 
commandement du bien et du pourchas du mal» mais tue dans le code de conduite qu'il énonce dans « Le livre des secrets de la pureté » (voir plus loin au sujet de ce dernier). Une seconde erreur a été commise par l'éminent orientaliste : voulant expliquer l'opposition des juristes musulmans au hammâm, il invoque l'influence des rabbins ${ }^{19}$. Certes l'aniconisme islamique a des liens avec le judaïsme rabbinique, mais, répétons-le, c'est seulement très tardivement que cette question a été associée à la critique des bains publics.

Sur le premier point, celui qui concerne les images, la littérature de traditions, dont H.L. connaissait pourtant l'essentiel ${ }^{20}$, apporte un démenti clair à ses assertions. Pourquoi, malgré ces nombreux textes où la mise en cause du hammâm est exclusivement liée au problème de la nudité, H.L. maintient-il cette explication ? Est-ce pour dénier toute originalité aux juristes musulmans, dont il ne fait dans ce domaine que les imitateurs dociles des rabbins ? Ce que H.L. n'a pas été en mesure de saisir est que la dénonciation par les autorités musulmanes du hammâm se rattache non au judaïsme rabbinique, qui est très favorable au bain public depuis l'époque romaine, mais au christianisme, qui a approfondi et systématisé la critique stoïcienne du bain public.

Selon H.L., alors que Muhammad n'avait manifesté aucune hostilité particulière envers les représentations figurées, les juristes musulmans, héritiers du judaïsme rabbinique, avaient suivi ce dernier aveuglément. Cette interprétation ne résiste pas à la confrontation avec les nombreuses traditions qui ont trait au hammâm : comme on vient de l'indiquer, dans aucune d'entre elles, il n'est question des peintures murales qui couvrent les murs des bains publics.

Alors qu'il cherche à dresser la liste des principaux comportements condamnables (munkarât) en relation avec la fréquentation du

19. «À ce titre, écrit-il imprudemment, les bains publics avaient déjà encouru la réprobation des rabbins. La Tradition musulmane s'est empressée de reprendre l'interdiction rabbinique et pour le même motif » (Lammens, Études, p. 372).

20. Il ne connaissait qu'indirectement - par les maigres citations qu'on rencontre dans de nombreux ouvrages - les deux grandes compilations de 'Abd al-Razzâq (m. 211/826) et de Ibn Abî Shayba (m. 235/849), qui n'ont été éditées que dans la seconde moitié du $\mathrm{XX}^{\mathrm{e}}$ siècle. 
hammâm, Ghazzâlî en dénombre cinq, parmi lesquels il signale le fait de tolérer la présence d'images représentant des animaux sur les murs et les portes des bains publics :

Il y a les images (suwar) qui ornent les portes et l'intérieur des bains publics. Celui qui s'y rend devra les faire disparaitre si cela lui est possible. Si elles sont inaccessibles, parce que trop hautes, il ne lui est pas permis d'entrer dans ce hammâm sauf en cas d'impérieuse nécessité (li-dharûra). Il devra donc se diriger vers un autre hammâm, car regarder des choses condamnables n'est pas permis. Il lui suffira de défigurer les faces, cela leur ôtera toute valeur. On n'interdit pas cependant les représentations des arbres et autres motifs de ce type, excepté celles d'animaux. ${ }^{21}$

Tous les juristes n'emboîteront pas le pas à Ghazzâlî au sujet de la présence condamnable d'images d'animaux dans les bains. Parmi ceux qui ne tiendront pas compte des sérieuses réserves émises par lui, on relèvera le nom d'un illustre shâficite comme Nawawî (m. 667/ 1273), qui écrit qu' «il n'y a pas de mal à fréquenter le hammâm dont la porte est couverte d'images $»^{22}$. Parmi ceux qui suivront Ghazâlî, il y a les hanbalites. Ibn Qudâma (m. 620/1235) n'énonce pas une règle claire et se cantonne à rappeler la recommandation de Ibn Hanbal de défigurer les représentations animales ${ }^{23}$. Ibn Taymiyya (m. 728/1328), par ailleurs sincère défenseur du hammâm, rangera les images d'animaux parmi les choses détestables ${ }^{24}$. On doit également citer le mâlikite Ibn al-Hâjj (m. 737/1336), un des plus virulents adversaires du hammâm: "Les images qui ornent leurs portes et leurs murs sont parmi les choses haïssables qui sont caractéristiques des bains publics, écrit-il. Le moins que l'on puisse exiger [du croyant] est de les défigurer en effaçant les têtes ${ }^{25}$. Quant à l'Imâm zaydite

21. Ghazzâlî, Ihyâ' 'ulûm al-dîn, Damas, s.d., II, 297 ; L'obligation d'ordonner le bien et d'interdire le mal (Ihyâ', II, xix), trad. de Léon Bercher, Publications de IBLA, Tunis, 1961, 68.

22. Rawdhat al-tâlibîn, éd. Abd al-Mawjûd et Mucawwad, Beyrouth, 1992, $\mathrm{V}, 650$.

23. Al-Mughnî, Le Caire, 1992, X, 205. Dans un autre passage, il écrit : «Pénétrer dans un lieu dans lequel il y a des images n'est pas défendu » (op. cit., 202).

24. Fatâwâ, Rabat, s.d., XXI, 300 (wa min al-munkarât al-latî yakturu fìhâ taswîr al-hayawân fî̀ hîtânihâ wa hadâ muttafaq calayhi).

25. Op. cit., I, 358. 
al-Mu'ayyad bi-llâh Yahyâ b. Hamza (m. 749/1348), dont Le livre de la purification des cours recopie à certains endroits des passages entiers de l'ouvrage de Ghazâlî, il le suit tellement de près qu'il donne exactement la même liste des cinq fautes à corriger au sujet du hammâm. L'une d'elles concerne les représentations figurées.

La première forme de mal (munkar) se rapporte aux images d'animaux sur les murs et dans les chambres, extérieures et intérieures des bains publics. On doit s'efforcer de changer (taghyîr) cela ; pour ce faire, il suffit de couper les têtes [des animaux] et de les en séparer, ou de les défigurer afin que ces représentations perdent de leur force. On ne doit pas cependant interdire les images d'arbres, car elles sont permises. Si [le fidèle] ne peut rien changer, il devra se rendre à un autre hammâm, car le spectacle de ce mal n'est pas permis ${ }^{26}$.

Il est notoire que les images et les statues abondaient dans les thermes romains. Quand, au vie/XII siècle, Ghazzâlî dénonce cette présence, cela ne peut vouloir dire qu'une chose : de nombreux bains, sans aucun doute bâtis après l'avènement de l'islâm, ont perpétué cet usage. Peut-être que des bains dépourvus d'images étaient-ils inconcevables aux yeux des baigneurs. Cela veut dire également que ni les gouvernants ni les autorités religieuses ne s'étaient préoccupés jusque-là de la conformité de la décoration des bains publics avec les préceptes de la loi islamique en matière de représentation figurée. Il est significatif que pas une fois la littérature de traditions, qui est certainement une des plus anciennes, n'évoque cet aspect. Il est même surprenant que les adversaires du hammâm n'aient pas ajouté cette critique à leur réquisitoire. Ce problème relève cependant de l'histoire de l'image en islâm ; on ne peut donc l'aborder ici. Enfin, il n'est pas certain absolument qu'à l'époque de Yahyâ b. Hamza, dans le Yémen zaydite du VIII/XIV siècle, on continuait à peindre sur les murs et les portes des bains publics; il se peut qu'il se soit contenté de plagier Ghazzâlî sans chercher à décrire la réalité de son temps et de son pays.

Ce que H.L., qui avait sans doute en tête le texte de Ghazzâlî (donc un ouvrage datant $\mathrm{du} \mathrm{VI}^{\mathrm{e}} / \mathrm{XII}^{\mathrm{e}}$ siècle), n'a pas vu, c'est que si la critique musulmane du bain public s'enracine dans une tradition

26. Kitâb tasfiyat al-qulûb, Sanaa, 1988, 524. 
ancienne, ce ne peut être celle du judaïsme, mais au contraire celle du christianisme. En effet, les rabbins ne sont pas aussi opposés qu'il le dit aux bains. Le Talmud, qui rapporte le propos iconoclaste d'un rabbin ${ }^{27}$, va jusqu'à défendre à un savant de résider dans une ville dépourvue de bains publics ${ }^{28}$. Le rabbin Hillel tenait la fréquentation du bain public pour un devoir religieux ${ }^{29}$. Alors qu'en Europe, les bains n'ont cessé depuis le Moyen-Âge de subir les foudres de la critique, les communautés juives y sont demeurées attachées ${ }^{30}$. Par ailleurs, certains détails semblent indiquer que les juifs ont adopté en grande partie les usages romains. Ainsi on considère que le bain chaud doit être suivi par un bain d'eau froide ${ }^{31}$; et il est recommandé de faire suivre le bain par une onction ${ }^{32}$. Ce sont des usages romains. Les rabbins n'étaient pas du tout hostiles à la fréquentation du bain public, dont ils ne se lassaient pas de vanter les mérites. Ils étaient bien plus romanisés que les Pères de l’Église de ce point de vue ! 33

L'hostilité des juristes musulmans aux images dans les bains publics doit être rapportée aux théories défendues par les médecins.

27. Qui commandait: «va et brise toutes les idoles qui se trouvent aux bains publics », cité par N. Belayche, in Nicole Belayche et Simon Claude Mimouni (éd.), 2003, Les communautés religieuses dans le monde gréco-romain. Essais de définition, Brepols, 139.

28. « Il est interdit de vivre dans une ville dépourvue de maison de bains » (cité par Albert Cohen, Le Talmud, Payot, 1991 [1950], 301).

29. "Quand il avait terminé la leçon qu'il donnait à ses élèves, il les accompagnait une partie du chemin. Ils lui disaient: Maître, où vas-tu ? Accomplir un devoir religieux. - Lequel ? - Prendre un bain. - Est-ce un devoir religieux ? - Si quelqu'un, répondait-il, est chargé de gratter et de nettoyer les statues du roi qui se dressent dans les théâtres et les cirques, si on le paye pour ce travail et si ensuite il est associé à la noblesse, combien plus dois-je prendre soin de mon corps, moi qui suis créé à l'image et à la ressemblance divines ! » (cité par Cohen, op. cit., 298).

30. Encyclopaedia Judaica, Jérusalem, 1971, IV, notice Bath, bathing, 319a-320a. Cf. aussi Pierre Aupert : "Les thermes comme lieu de culte », in Les thermes romains, Collection de l'École française de Rome, 1991, 192 ${ }^{\text {b. }}$

31. Cohen, op. cit, 301.

32. Cohen, op. cit., 302. «Il convient, déclare un traité talmudique, de baigner les bébés et de les frictionner avec de l'huile».

33. Sur l'attitude du judaïsme rabbinique à l'égard du bain public, voir les références données dans Benkheira, op. cit., 429, note 175. 
Selon ces derniers, d'après le yéménite al-Haymî (m. 1152/1740), les images jouent un rôle important dans la fonction thérapeutique du bain : elles contribuent à détendre le baigneur et lui procurent du plaisir. Ces images doivent représenter principalement des motifs empruntés à la vie de la nature (jardins, arbres, animaux sauvages). C'est l'accord entre ces sujets et l'âme du baigneur qui octroie à ce dernier le délassement ${ }^{34}$. En somme, le hammâm n'a pas trait seulement au corps physique, mais agit également sur la vie psychique. C'est sans doute contre cette dimension que s'insurgent les juristes : ce n'est pas aux images à procurer le repos mais seulement à la religion.

\section{LA TRADITION PROPHÉTIQUE ET LE HAMMÂM}

Il n'y a aucune référence au hammâm dans le Coran. Seule la littérature de traditions (hadît ) l'évoque. ${ }^{35}$ Nous commencerons par là parce que même si cette littérature ne date au sens propre du mot que du $\mathrm{III}^{\mathrm{e}} / \mathrm{IX}^{\mathrm{e}}$ siècle, nous sommes en droit de penser qu'elle a fixé et transmis des opinions remontant au moins au siècle précédent. Globalement, il ressort d'un examen aussi minutieux que possible de cette littérature qu' aucune défense ferme de fréquenter le hammâm n'est associée à Muhammad. Alors que l'on relève dans la littérature d'obédience sunnite de nombreuses réserves, voire des critiques à l'endroit du hammâm, la littérature imâmite se présente elle comme beaucoup mieux disposée envers le hammâm. Comme on va le voir dans un instant, s'il existe du côté sunnite, des traditions dans lesquelles Muhammad fait mine d'interdire à tous le hammâm, puis, se ravisant, permet sa fréquentation sous certaines conditions

34. Al-Haymî, Hadâ'iq al-nammâm fî al-kalâm calâ mâ yatacallaq bi-lhammâm, éd. Habshî, République Arabe du Yémen, Wizârat al-awqâf wa-l-irshâd, s.d., 28-30. Voir également les remarques d'Ibn Butlân : Elkhadem, op. cit., 276.

35. De nombreuses traditions, prophétiques ou non, qui ont trait au hammâm sont rassemblées dans la grande encyclopédie de al-Muttaqî al-Hindî (m. 975/ 1 567), Kanz al-c ummâl, Beyrouth, 1998, IX, 169-72 et 244-5. Nous n'examinons pas ici les traditions ayant trait à la question de la pureté, déjà étudiées dans notre précédente publication signalée plus haut. 
spécifiques à chacun des sexes, de telles traditions sont totalement absentes dans la littérature de traditions imâmite (voir plus loin). On prête à ${ }^{\mathrm{c}} \mathrm{Alî} \mathrm{b}$. Abî Tâlib, le Ir Imâm chiite, un seul propos défavorable au hammâm : «Le hammâm est la pire des maisons, il déchire toute protection (sitr) et entraîne la perte de toute pudeur $»^{36}$. Aussi sévère que soit ce propos, il n'interdit pas sa fréquentation aux fidèles, même pas aux femmes, il insiste seulement sur les dangers qu'il recèle. La littérature sunnite semble plus divisée : on y trouve un unique texte en faveur de l'interdiction (voir paragraphe suivant), plusieurs textes prônant de l'interdire aux femmes et d'autres en plus grand nombre soumettant sa fréquentation à des conditions pour les deux sexes. On peut suggérer l'hypothèse que les textes en faveur de l'interdiction du hammâm pour tous les fidèles ou seulement pour les femmes datent d'une époque très ancienne et sont la partie immergée d'un débat primitif, à une époque où la distinction entre sunnites et chiites n'avait pas encore cours. Quand les imâmites se sont constitués comme communauté distincte, tardivement, au cours des III $/ \mathrm{IX}^{\mathrm{e}}$ et IV $/ \mathrm{X}^{\mathrm{e}}$ siècles, et qu'ils se sont dotés de leur propre corpus de traditions, ils n'ont pas retenu au sujet du hammâm des textes qui étaient depuis devenus obsolètes, puisque la doctrine à ce sujet était déjà globalement définie. Ils n'ont donc retenu que les traditions qui allaient dans le sens de cette doctrine. Quand aux sunnites, plusieurs raisons expliquent la présence dans leur corpus des textes les plus hostiles au hammâm. Leur corpus est de constitution plus ancienne : pour l'essentiel, il date de la première moitié du III//IX siècle, alors que celui des imâmites n'a commencé à être constitué qu'à partir $\mathrm{du} \mathrm{IV}^{\mathrm{e}} / \mathrm{X}^{\mathrm{e}}$ siècle. Il y a également une autre raison, certainement plus décisive. L'élaboration et la propagation des traditions, prophétiques ou non, sont à mettre sur le compte d'un groupe religieux particulier : les ahl al-hadît. Hormis le rôle décisif qu'il a joué dans la constitution de la littérature de traditions islamique, ce groupe défendait des positions anti-rationalistes, piétistes et souvent ascétiques. Ce groupe, qui a été surtout actif durant le $\mathrm{II}^{\mathrm{e}} / \mathrm{VIII} \mathrm{e}^{\mathrm{e}}$ siècle, a eu de nombreux héritiers dans les milieux

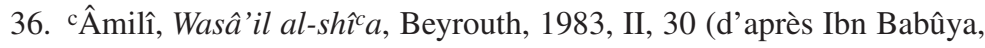
Man lâ yahdhuruhu al-faqîh, Beyrouth, I, 63, n² 238). 
sunnites. Un des plus brillants et des plus ardents d'entre eux fut Ahmad b. Hanbal (m. 241/855), qui fit école et eut de nombreux disciples et élèves tout en jouant un rôle de premier plan dans l'histoire du hadith ${ }^{37}$. C'est à eux principalement que l'on doit la conservation des traditions les plus hostiles au hammâm.

\section{La défense de fréquenter le hammâm}

Dès le Ir/VII siècle, comme en témoignent à la fois l'archéologie et l'historiographie musulmane, des bains existaient dans le monde islamisé : non seulement beaucoup de ceux qui ont été hérités de la période byzantine ont continué à fonctionner, mais les musulmans en ont construit également. On doit éviter de confondre les positions défendues par les hommes de religion et les comportements de leurs contemporains, qu'ils fassent partie du peuple ou des élites économiques, militaires ou politico-administratives. Il en est du hammâm comme il en est, toutes proportions gardées, du vin : l'interdit coranique qui frappe ce dernier n'a nullement empêché, à quelque époque que ce soit et dans toutes les contrées, de nombreux musulmans d'en consommer jusqu'à l'ivresse.

Les traditions défendant absolument, à tous les croyants, la fréquentation du hammâm sont rares. Je n'en ai relevé qu'une seule, dans une collection de traditions prophétiques qui n'a pas une portée juridique stricto sensu et qui ne fait pas partie des collections canoniques. Il s'agit des $S h u^{c} a b$ al-îmân du shâficîte Bayhaqî (m. 458/ 1065). Cette tradition a été transmise par le Yéménite Tâwûs b. Kaysân (m. 106/724) :

(i) « Je vous défends [de vous rendre dans] une maison appelée hammâm $»^{38}$.

Il s'agit d'un hadith que les spécialistes musulmans classent comme mursal, c'est-à-dire que manque dans la chaîne de transmission (isnâd), l'élément intermédiaire entre Muhammad - qui est sensé être l'auteur du propos - et Tâwûs. Or selon une hypothèse

37. Voir Nimrod Hurvitz, The formation of hanbalism. Piety into power, Routledge Curzon, 2002.

38. Bayhaqî, Shucab al-îmân, Beyrouth, 1990, VI, 155, nº 7766. 
défendue par J. Schacht, les hadiths de ce type sont des opinions de juristes qui sont mises a posteriori sur le compte du prophète de l'islâm afin de leur octroyer une plus grande autorité. Dans cet ordre d'idées, il y a une forte probabilité pour que le propos soit le fait de Tâwûs, et que ce sont ses successeurs, peut-être son propre fils ou plus probablement Ayyûb al-Sahtiyânî (m. 131/749), qui l'ont mis sur le compte de Muhammad, car à leur époque, pour le groupe des ahl al-hadît dont ils faisaient partie, il était la source de la norme légitime. Et si un élément manque dans la chaîne de transmission (isnâd), c'est parce qu'à cette même époque, on n'avait pas encore défini rigoureusement les formes canoniques de la chaîne des garants.

Une autre tradition a été transmise par 'Atâ' b. Abî Rabâh (m. 114/732), grand juriste mecquois, presque contemporain de Tâwus :

(ii) «Le hammâm est la pire des maisons ; l'on ne peut s'y couvrir et son eau ne purifie pas $\gg{ }^{39}$.

Ce second texte associe deux critiques majeures du bain public par les juristes et les moralistes musulmans. Cependant il est moins tranché : il peut être compris non comme une interdiction mais seulement comme une réprobation de la fréquentation du bain public. À la différence de la seconde tradition, la première repose sur le présupposé que les destinataires du propos ne connaissent pas le hammâm.

Comme aucune de ces traditions ni rien de semblable ne figure dans les collections canoniques, qui sont la principale source de la $\operatorname{sharî}^{c} a$, on peut faire l'hypothèse qu'elles sont l'expression d'une attitude très ancienne, qui remonte à la fin du $\mathrm{I}^{\mathrm{er}} / \mathrm{VII}^{\mathrm{e}}$ siècle ou au tout début $\mathrm{du} \mathrm{II}^{\mathrm{e}} / \mathrm{VIII}^{\mathrm{e}}$ siècle et qui a été ensuite abandonnée. Étaitelle partagée par tous les juristes ou était-elle propre à une catégorie particulière d'entre eux? Nous l'avons montré dans la première partie de cette étude, un grand nombre d'hommes de religion, et

39. Bayhaqî, op. cit., 158, $\mathrm{n}^{\circ} 7772$. Il existe de nombreuses versions de cette tradition, surtout dans la littérature sunnite. La plupart du temps elles sont attribuées à Muhammad lui-même. Ainsi celle-ci, rapportée par Tabarânî : «Le hammâm est la plus funeste des maisons ; on y élève la voix et on s'y dénude » (Ibn Hajar al-Haytâmî, Al-zawâjir can iktirâf al-kabâ'ir, Le Caire, 1994, I, 278). 
pas seulement des juristes, étaient hostiles au bain public, à telle enseigne qu'on dit qu'ils n'y ont jamais les pieds. Ils étaient tous proches du groupe des ahl al-hadît, qui défendait souvent des positions théologiques et morales piétistes. L'absence de tout hadith prohibitionniste dans les grandes collections canoniques indique que, dès la première moitié $\mathrm{du} \mathrm{III}^{\mathrm{e}} / \mathrm{IX}^{\mathrm{e}}$ siècle, les adversaires du hammâm perdent beaucoup de terrain et que les oulémas cessent de condamner sa fréquentation, changeant ainsi de stratégie à son égard. Voyant qu'ils ne pouvaient réussir à imposer son évitement, qui aurait entraîné à terme sa disparition, ils ont préféré agir sur ses adeptes en assujettissant sa fréquentation à des règles précises. Ibn Hanbal, on va le voir, est, parmi les hommes de religion du $\mathrm{III}^{\mathrm{e}} / \mathrm{IX}^{\mathrm{e}}$ siècle, celui qui est demeuré le plus attaché à l'ancienne conception ; c'est pour cela qu'à cette époque, il est sans aucun doute le principal représentant du courant hostile au hammâm. L'École qui va se réclamer de son héritage n'en va pas moins admettre la licéité de la fréquentation du hammâm, insistant peut-être plus que les autres sur des aspects condamnables. Un exemple suffira amplement pour témoigner de cette évolution. On ne peut soupçonner Ahmad b. Taymiyya d'être laxiste ou permissif : selon lui, il est impossible que Ibn Hanbal ait envisagé l'interdiction complète des bains, cela serait « en contradiction avec les principes de la $\operatorname{sharî}^{c} a »^{40}$.

\section{La prescription de la décence}

Pourtant, le projet d'interdire la fréquentation du hammâm ne va pas totalement disparaître : s'il est totalement abandonné concernant les hommes, des juristes vont continuer à le défendre pour ce qui concerne les femmes. Des hommes, ils se contentent d'exiger qu'ils se vêtissent d'un pagne. Et même pour les femmes, comme il sera difficile de faire accepter une défense absolue, on consentira une dispense pour celles auxquelles le médecin a recommandé le bain, pour la parturiente comme pour la menstruante. Ainsi nous avons affaire dès une époque ancienne à une double stratégie, qui évoluera lentement par la marginalisation de la plus radicale.

40. Ibn Taymiyya, op. cit., 301. 
Un premier groupe de traditions n'introduit pas de distinction entre les sexes :

(iii) Le Messager de Dieu a dit : «Craignez Dieu au sujet d'une maison qu'on appelle hammâm ! - Ô ! Messager de Dieu ! on y lave les saletés (wasah $)$ et il sert à cela ${ }^{41}$. - Que celui qui s'y rend, se couvre ! » [c'està-dire soyez décents] ${ }^{42}$.

(iv) Le Messager de Dieu a dit : « Le hammâm est la pire des maisons ». Quelqu'un ou plusieurs lui dirent : - Ô Messager de Dieu ! le malade s'y soigne et il permet de se débarrasser de la saleté. - Si vous faites cela, faites-le en étant couverts ! ${ }^{43}$.

Le fait est assez remarquable pour être noté : ces deux traditions (iii, iv) se rattachent aux deux précédentes (i, ii) sur le plan formel. En effet, de même que la (iii), celle rapportée par ${ }^{\mathrm{c}} \mathrm{Abd}$ al-Razzâq (i) comporte dans sa première partie une prédiction ; la (iv) et la (ii) comportent également un élément commun, à savoir un jugement moral («la pire des maisons»). La principale différence entre les traditions (iii, iv) et (i, ii) est que, alors que celles-ci comportent un propos condamnant le hammâm plus ou moins sévèrement, les autres se présentent comme un dialogue qui a pour objet le statut du hammâm du point de vue religieux. Dans un premier temps, Muhammad, censé parler, prévient les musulmans contre le hammâm. Un interlocuteur indéterminé lui oppose alors une objection qui met en valeur l'utilité et les services que rend le hammâm. En conclusion, Muhammad nuance son jugement et invite les fidèles à cacher leur bas-ventre quand ils s'y rendent. Cette structure est en apparence anodine : en fait nous avons sous les yeux, sous une forme raccourcie, le débat entre adversaires et défenseurs du hammâm au II $/ \mathrm{VIII}^{\mathrm{e}}$ siècle, avec l'issue qui est la résolution du conflit à travers la formulation d'une règle ayant trait à la nudité à l'intérieur du bain public.

41. Le texte de la tradition de Bayhaqî inclut la référence à la motivation médicale de la fréquentation du hammâm : «Il fait disparaître la crasse et profite au malade !».

42. ' $A b d$ al-Razzâq, Al-musannaf, éd. al-Aczamî, rééd. Beyrouth, 1983 [1970-1973], I, 290, n 1116 et $\mathrm{n}^{\circ} 1117$ (variante) ; Bayhaqî, op. cit., 155, $\mathrm{n}^{\circ} 7$ 765bis et 155-6, nº 7767 ; al-Hâkim al-Nîsâbûrî, Al-Mustadrak, Beyrouth, s.d., IV, 320, nº 7778 (version semblable à celle de Bayhaqî).

43. Bayhaqî, op. cit., 156, nº 7768 ; Nûr al-Dîn al-Haytamî, Majmac alzawâ'id wa manbac al-fawâ'id, Beyrouth, 1988, I, 277 (d'après Al-Bazzâr et Tabarânî). 
Dans les chaînes de transmission des traditions (iii) et (iv), on rencontre de nouveau Tâwûs b. Kaysân ; cependant cette fois il ne s'agit pas de formuler une interdiction de fréquenter le hammâm mais seulement la règle de se couvrir. Les chaînes de transmission sont tantôt interrompue (mursal), tantôt ininterrompue (la version de Bayhaqî). Si l'on accepte de considérer que le mursal doit être mis sur le compte du Suivant ${ }^{44}$ qui rapporte le supposé propos prophétique, on sera obligé de constater que l'attitude de Tâwûs face au hammâm semble être contradictoire : dans un cas, plus haut (i), il condamne le hammâm de façon claire, dans l'autre, celui-ci (iii, iv), il dispense les hommes de cette défense s'ils se couvrent. Il ne peut avoir soutenu ces deux positions simultanément. Les a-t-il soutenues à des moments différents de sa carrière, autrement dit sa pensée à ce sujet a-t-elle évolué ? C'est une possibilité, mais rien ne permet de l'affirmer avec certitude. L'un des deux transmetteurs suivants - Sufyân ou même cAbd al-Razzâq, l'auteur de la compilation, luimême yéménite - peut être responsable de cet infléchissement.

Ces traditions, qui se présentent sous la forme d'un dialogue entre Muhammad et des fidèles, sont composés de deux parties : dans la première, il édicte la défense de fréquenter le hammâm plus ou moins explicitement ; dans la seconde, ayant tenu compte des objections de ses interlocuteurs, il substitue à l'interdiction absolue la règle de couvrir sa nudité. Les traditions construites sur ce modèle pédagogique sont nombreuses. Les deux arguments qui sont avancés pour défendre le hammâm sont la propreté et la santé. On notera que les interlocuteurs (fictifs ?) de Muhammad n'évoquent pas la purification rituelle, car comme nous l'avons montré dans la première partie de cette recherche, elle a généralement lieu à domicile, ou dans une quelconque étendue d'eau (rivière, étang, mare, source). Cela veut dire que si ces textes datent $\mathrm{du} \mathrm{II}^{\mathrm{e}} / \mathrm{VIII} \mathrm{e}^{\mathrm{e}}$ siècle, alors dès cette époque on se rendait au bain soit pour être propre - et non en vue de la purification rituelle -, soit sur recommandation du médecin. L'historiographie confirme nettement cette conclusion. Prétendre que les musulmans

44. Dans la langue technique du hadith, les Suivants sont les disciples des Compagnons de Muhammad. 
n'ont adopté le bain public que parce qu'il leur permettait de satisfaire aux rites de la purification est une méprise évidente. Or c'est à peu près pour les mêmes raisons que les Romains et ensuite les Byzantins fréquentaient les thermes. Du reste, quand les Pères de l'Église décident de s'en prendre à l'habitude de fréquenter le bain public, ils ne peuvent s'opposer à sa fréquentation pour raison de santé. Il ressort que les musulmans des deux premiers siècles étaient encore fortement marqués par la culture païenne du bain public.

\section{Interdire le hammâm aux femmes?}

L'opposition au hammâm n'ayant pu conduire à son rejet total, et après avoir imposé, dans le cadre d'un usage non mixte, des règles de décence, va vainement tenter d'obtenir son interdiction pour les femmes. Nous allons voir comment.

Aucune des traditions examinées précédemment ne fait allusion à une double règle, l'une propre aux hommes, l'autre aux femmes. C'est dans ce silence, difficile à interpréter, que va s'enraciner la volonté d'interdire la fréquentation du bain public aux femmes. D'autres juristes, vont préférer à la solution radicale - interdiction totale et absolue - une solution plus équilibrée, qui laisse place à la casuistique en admettant des motifs de dispense.

- Le bain public est interdit aux femmes, même vêtues d'un pagne.

Deux traditions, présentes dans plusieurs collections importantes, défendent explicitement la fréquentation du hammâm aux femmes :

(v) «Le Prophète a défendu les bains aux hommes et aux femmes; ensuite il a accordé aux hommes la dispense pour y entrer revêtus d'un pagne (mayâzir), mais non point aux femmes ${ }^{45}$.

45. Ibn Hanbal, Musnad, éd. Muhammad ${ }^{\mathrm{c}} \mathrm{Abd}$ al-Salâm ${ }^{\mathrm{c}} \mathrm{Abd}$ al-Shâfî, Beyrouth, 1993, VI, 148, n 25059 [132] ; 156, n² 25138 [139]; 200, n 25510 [179] ; Ibn Mâja, Sunan, avec les gloses de Al-Busîrî et de Sanadî, éd. Shîhâ, Beyrouth, 1997, IV, 224-5, n 3749 ; Ibn al-c'Arabî/Tirmidî, ${ }^{c} \hat{A}$ ridhat al-ahwad $\hat{\imath}$ bi-sharh Sahîh al-Tirmidîl, Beyrouth, 1997, X, 182, nº 2802 ; Âbâdî/Abû Dawud, 'Awn al-ma cbûd sharh Sunan Abî Dâwûd, Beyrouth, 1997, XI, 31, $\mathrm{n}^{\circ} 4002$; Bayhaqî, op. cit., 155, n 7 765a, sans le fragment sur les femmes, via Abû Dâwûd. 
(vi) Le Prophète a dit : Celui qui croit en Dieu et au Jour Dernier ne doit pas pénétrer dans le hammâm sans pagne ${ }^{46}$. Il ne doit pas y faire entrer son épouse légitime (halîla) ${ }^{47}$. Il ne doit pas non plus s'asseoir à la table où l'on boit du vin ${ }^{48}$.

La tradition (v) présente la défense de fréquenter le hammâm pour tous les musulmans, comme ayant été abrogée ensuite par Muhammad lui-même concernant les hommes à condition qu'ils enfilent un pagne. La levée de la défense ne concerne point les femmes. La conjonction sert à indiquer qu'il y a eu évolution dans l'attitude du prophète de l'islâm, sans faire référence à une discussion argumentée. L'inventeur probable de cette tradition est Hammâd b. Salama (m. 167/

46. Dans la variante de Nasâ'î : illâ bi-mi'zar. Dans la variante compilée par Bayhaqî, on lit : "Que celui qui croit en Dieu et au Jour dernier soit généreux avec son voisin ! Que celui qui croit en Dieu eu Jour dernier fasse preuve de générosité avec son hôte ! Que celui qui croit en Dieu et au Jour dernier dise le bien ou garde le silence ! Que celui qui croit en Dieu et au Jour dernier n'entre au hammâm que couvert d'un pagne ! Que celles qui croient en Dieu et au Jour dernier parmi les musulmanes n'aillent point au hammâm ! » (Bayhaqî, op. cit., 156-7, $\mathrm{n}^{\circ} 7769$ ).

47. Dans plusieurs variantes, il est question des musulmanes en général (par exemple, Bayhaqî - note précédente - ou Ibn Hajar al-Haytamî, op. cit., 277-8).

48. Tirmidî, op. cit., 181, n 2801 ; Ibn Hanbal, op. cit., I, 26, nº 126 [20], II, 430, nº 8295 [321], III, 416, nº 14663 [339] ; Nasâ'î, Sunan, avec gloses de Suyutî et Sanadî, Le Caire, s.d., I, 198, variante qui ne comprend que la première phrase ; Abû Yaclâ al-Mawsilî, Musnad, éd. 'A Abd al-Qâdir ${ }^{\mathrm{c}}$ Atâ, Beyrouth, 1998, II, 247, n 1921 ; Hâkim, op. cit., IV, 320-1, n 7779 et 321-2, $n^{\circ} 7783$ (version différente et plus longue) ; Ibn Habîb, Kitâb adab al-nisâ', éd. Abdelmagid Turki, Beyrouth, 1992, 233, $\mathrm{n}^{\circ} 155$, sans le fragment sur le vin ; Tabarânî, Al-mucjam al-kabîr, éd. Hamdî 'Abd al-Majîd al-Salafî, Baghdâd, s.d., XI, 153, n 11462 ; Bayhaqî, op. cit., 157, nº 7770 ; Nûr al-dîn al-Haytamî, $M_{a j m a}{ }^{c}$, I, 277, ainsi que Ibn Hajar al-Haytamî (à ne pas confondre avec le précédent), op. cit., 278, version sans le fragment sur le vin (d'après Ibn Hanbal) et 278 (d'après Al-Bazzâr et Tabarânî) (version longue contenant incise sur la prière du vendredi, mais non le fragment sur le vin). Dans la tradition de Tabarânî ( $\mathrm{n}^{\circ} 11$ 462), après l'énoncé sur le hammâm, il y a un énoncé prohibant la consommation de vin avant le fragment sur la réunion où a lieu cette consommation, et pour finir l'énoncé de la défense de demeurer seul ( $h a l w a$ ) avec une étrangère. Nûr al-dîn al-Haytamî rapporte une autre version d'après Tabarânî, qui comporte plusieurs fragments supplémentaires (sur les obligations envers l'hôte et le voisin) mais non le fragment sur le vin. 
784), un traditionniste de Basra. Ce personnage est déjà présent dans une des chaînes de transmission du hadith sur « La terre entière est un oratoire sauf le hammâm et le cimetière ${ }^{49}$. Il est présenté comme un des abdâl de son temps. Grand connaisseur de la langue arabe, il est également qualifié de sâhib sunna. ${ }^{50} \mathrm{Il}$ est évident qu'il doit être rangé parmi ces fameux ahl al-hadît. Il blâmait la quête du hadith dans un but non religieux. Lui-même prétendait avoir vu en rêve le célèbre traditionniste Ayyûb al-Sahtiyânî, qui lui aurait alors commandé d'enseigner le hadith. Bien qu'on puisse le qualifier de traditionnaliste et même le soupçonner de puritanisme, il a épousé, selon des dires, soixante-dix femmes, mais est demeuré sans descendance. Il a eu quelques élèves prestigieux comme ${ }^{\mathrm{c}} \mathrm{Abd}$ Allâh b. alMubârak (m. 181/797) ou Yahyâ al-Qattân (m. 198/813) ${ }^{51}$. Ceux qui, après lui, ont diffusé cette tradition sont la plupart du temps des gens de Basra comme lui : 'Affân b. Muslim (m. 220/835), qui s'installera à Baghdâd, un partisan des ahl al-hadît et un adversaire résolu de la doctrine créationniste du Coran ${ }^{52}$, le célèbre traditionniste ${ }^{\mathrm{c}} \mathrm{Abd}$ alRahmân b. Mahdî (m. 198/813), et Mûsâ b. Ismâcîl (m. 223/837). Un seul de ces transmetteurs n'est pas de Basra mais de Kûfa, c'est Wakîc b. al-Jarrâh (m. 196/812), fameux personnage, croisé précédemment, qui a suscité l'admiration d'Ahmad b. Hanbal, malgré des accusations de chiisme et bien qu'il fut un disciple de Abû Hanîfa dans le domaine juridique. ${ }^{53}$

49. Voir Benkheira, op. cit., 420-1.

50. Sur cette expression, cf. Gauthier Juynboll, Studies on the origins and uses of islamic hadith, Londres : Variorum, 1996, texte $\mathrm{n}^{\circ} \mathrm{V}, 113-7$.

51. Dahabî, Tadkirat al-huffâz, Beyrouth, 1998, I, 151, nº 197 ; Ibn Hajar, Tahdî̀b al-tahdî̀b, Beyrouth, 1996, I, 481-3.

52. Ibn Hajar, op. cit., III, 117-9.

53. Il aurait déclaré à son propos : « Je n'ai jamais rencontré quelqu'un qui soit comparable à Wakî̀ $\hat{i}^{c}$ pour la mémorisation [du hadîth], pour [la qualité de ses] chaînes de transmission, pour [sa connaissance] de la matière [du fiqh], en sus de la crainte [de Dieu] et du scrupule » (Ibn Hajar, op. cit., IV, 312). Il déclina la proposition que lui fit le Calife de Baghdâd de devenir juge et rompit avec son condisciple Hafs b. Ghiyât à cause de cela (Benkheira, op. cit., 433). 
La tradition (vi) met en relation la foi (îmân) et la fréquentation du hammâm. Le croyant ne doit y entrer que revêtu d'un pagne, de même qu'il ne doit pas permettre à son épouse d'y aller, comme, analogiquement, il ne doit pas s'asseoir à une table où l'on consomme des boissons enivrantes. Il s'agit là encore d'un modèle rhétorique redondant dans la littérature de traditions : beaucoup de hadiths commencent par la formule rituelle «Celui qui croit au Jour Dernier... ». On retiendra : $1^{\circ}$ Au moment où cette tradition est mise en circulation, il est admis que la fréquentation du hammâm est permise aux hommes qui portent un pagne. Nous sommes donc loin de l'époque où cette fréquentation était encore sujette à caution : aller au hammâm, pour un homme, ne remet en cause sa foi que s'il évolue entièrement nu, sous le regard d'autrui. $2^{\circ}$ Cependant il ne doit pas permettre à sa femme de s'y rendre : ce rappel implique-t-il qu'à l'époque de l'élaboration de cette tradition les femmes fréquentaient déjà le hammâm sans que les époux ne puissent s'y opposer ou n'y voient de mal ? La menace dans ce texte pèse sur les hommes, non sur les femmes : car c'est à l'autorité des premiers sur les secondes qu'il fait appel. $3^{\circ} \mathrm{La}$ tradition met souvent côte à côte plusieurs défenses, dans la version la plus courante, il est question de ne pas s'attabler avec des hommes qui sont en train de consommer des boissons alcoolisées. $4^{\circ}$ Enfin, dans la mesure où cette tradition ne figure dans aucune autre collection pré-canonique hormis celle d'Ibn Hanbal, on peut penser qu'elle lui est due, ou qu'elle est née dans son entourage, ou au moins dans des cercles hanbalites de Baghdâd, soit environ au cours du premier tiers du $\mathrm{III}^{\mathrm{e}} / \mathrm{IX}^{\mathrm{e}}$ siècle. Si on admet cette chronologie, cela voudrait dire qu'à cette époque le débat porte principalement sur la fréquentation du bain public par les femmes. Il ressort également que les adeptes de la prohibition se recrutent surtout parmi les milieux ascétiques, dont Ibn Hanbal est un des plus illustres représentants.

On va le voir, les traditions opposées à la fréquentation du bain public par les femmes sont nombreuses, mais ces deux dernières ont la particularité de souligner la différence entre hommes et femmes face à cette question : le hammâm est interdit aux femmes, sans aucune dispense, mais non aux hommes, auxquels il est demandé de 
porter un pagne ${ }^{54}$. Comment expliquer cette différence de traitement ? Il ressort avec beaucoup de clarté que le plus grand problème posé par le hammâm a trait à la nudité physique. Dans cette perspective, il apparaît qu'il est plus difficile d'accepter que la femme se dénude, même si ce n'est qu'au milieu de femmes et même si elle cache ses parties.

- «Déchirer le voile entre elle et son Seigneur».

D'autres traditions attestent que les traditionnistes s'opposaient à la fréquentation du hammâm par les femmes, même si elles demeuraient entre elles :

(vii) ${ }^{\mathrm{A}} \hat{\mathrm{A}}$ 'isha a interrogé un jour le Messager de Dieu au sujet de la fréquentation du hammâm : - Il y aura après moi [après ma mort] des hammâms, or il n'y a aucun bien dans le hammâm pour les femmes. - Ô ! Messager de Dieu ! elles le fréquenteront en portant un pagne. - Non ! même si elles portent un pagne, une chemise $\left(\mathrm{dir}^{c}\right)$ et un foulard $(\text { khimâr })^{55}$. Toute femme qui ôte son foulard ailleurs que dans la demeure de son époux, ôte le voile entre elle et son Seigneur!56

Cette tradition paraît être une réponse à la tentative d'appliquer aux femmes les mêmes règles qu'aux hommes. Des juristes ont-ils tenté d'accorder la même permission aux femmes, pourvu qu'elles se couvrent ou ce texte est-il seulement le reflet d'une discussion purement théorique ? En tout cas, cette tradition exprime un point

54. On peut citer d'autres traditions prophétiques qui prônent l'interdiction de fréquenter le hammâm pour les femmes, mais qui ne figurent pas dans les grandes collections. Ibn Hajar al-Haytamî en signale plusieurs, sans toujours donner ses sources. «Le bain est illicite pour les femmes de ma communauté ». «Celles parmi vous qui croient en Dieu et au Jour Dernier ne devront pas mettre les pieds dans un hammâm ». «Les bains sont licites pour les hommes de ma communauté à condition qu'ils portent des pagnes et défendus pour les femmes de ma communauté ». «J'adjure au nom de Dieu les hommes de ma communauté de n'aller au hammâm que vêtus d'un pagne. J'adjure au nom de Dieu les femmes de ma communauté de ne pas se rendre au hammâm ». "Quand viendra la Fin des Temps, il sera défendu aux hommes de ma communauté de fréquenter les bains, même s'ils portent des pagnes. - Et pourquoi cela Ô Messager de Dieu ? - Car ils le fréquenteraient en même temps que des gens qui sont dénudés. Or Dieu n'a-t-il pas maudit le voyeur et l'exhibitionniste ?» (op. cit., 278-9).

55. Le himâr est le foulard dont la femme doit se couvrir la tête quand elle évolue dans l'espace public.

56. Nûr al-dîn al-Haytamî, op. cit., 278 (d'après Tabarânî). 
de vue franchement hostile à la fréquentation du hammâm par les femmes ; il n'y est même pas question de la dispense reconnue par d'autres hadiths à celles qui sont malades, à la menstruante et à la femme en couches. Ce texte, qui ne se trouve que dans la collection « moyenne » de Tabarânî (m. 360/970) et qui décalque partiellement le hadith sur la visite des femmes de Syrie à ' $\hat{A}$ 'isha, est sans aucun doute l'œuvre de ce dernier. ${ }^{57}$ De ce point de vue, il a pu être élaboré postérieurement au hadith sur les femmes d'Emèse (voir plus bas).

La tradition suivante est également l'œuvre de membres des mêmes cercles, peut-être même Ibn Hanbal (m. 241/855) ou son fils - car c'est dans sa collection qu'on la rencontre pour la première fois - ou certains de ses disciples :

(viii) Umm al-Dardâ' raconte : Un jour, sortant du hammâm, j'ai rencontré le Prophète. «D'où viens-tu, m'interrogea-t-il, ô Umm alDardâ' ? - Du hammâm, répondis-je. - Par Celui qui tient ma vie entre Ses mains, chaque fois qu'une femme ôte ses vêtements ailleurs que chez l'une de ses mères ${ }^{58}$, elle déchire le voile (sitr) qu'il y a entre elle et le Miséricordieux ${ }^{59}$.

Une des principales singularités de cette tradition est, en faisant référence à une rencontre dans la rue entre Muhammad et Umm alDardâ', qui n'a pu avoir lieu qu'à Médine, de laisser croire implicitement qu'il y avait des bains publics dans cette ville du vivant même du prophète de l'islâm. Cette tradition est en contradiction avec d'autres traditions qui présupposent exactement le contraire ainsi qu'avec de nombreux témoignages. À la veille de l'Hégire, les bains publics sont avant tout un trait de la civilisation romaine et ne se rencontrent pour cette raison que dans les régions romanisées du Moyen Orient. Or s'il ne fait aucun doute que la civilisation romaine

57. Tabarânî est un disciple de Ibn Hanbal.

58. On lit chez Qurtubî fì ghayr bayt ahad min ummahâtihâ (Al-jâmic li-ahkâm al-Qur'ân, Beyrouth, 1996, XII, 149). Ce passage est obscur. On s'attendrait à ce qu'il soit question de l'époux, car une épouse ne peut dévoiler sa nudité que dans le domicile conjugal. En plus, le pluriel est surprenant et complique le problème. Chez Qurtubî, la chaîne de transmission est quasiidentique au n ${ }^{\circ} 27803$ si ce n'est que Ibn Hanbal est remplacé par Ahmad b. Manîc.

59. Ibn Hanbal, op. cit., VI, 394, n 27803 [361], 27804 [362], 27806 [362] ; Nûr al-dîn al-Haytamî, op. cit., 277 (d'après Ibn Hanbal et Tabarânî). 
a exercé une certaine influence - qui ne doit pas cependant être exagérée - sur les populations et le mode de vie de la Péninsule arabique, on n'en a pas pour autant édifié des bains dans le Hijâz. Il y avait à cela deux obstacles majeurs. En premier lieu, on ne doit pas oublier une difficulté tenant au climat de cette région : les possibilités hydrauliques ne le permettent guère. En second lieu, le bain public n'est pas seulement un procédé technique pour l'hygiène, mais constitue surtout un dispositif culturel, qui suppose plusieurs prémices, dont l'idéal que constitue la propreté du corps physique, associée par les Romains à la fois à la beauté et à la santé. Au VII siècle de l'ère chrétienne, le Hijâz est encore marqué par une civilisation de nomades et de pasteurs, donc très éloignée des idéaux romains. Il ne fait guère de doute que nous avons affaire à une tradition inconnue avant Ibn Hanbal et dont la mise en circulation lui est due.

Deux autres éléments doivent être soulignés dans cette tradition. Il est manifeste qu'elle est dirigée contre la fréquentation du hammâm par les femmes. Elle ne fait nulle référence à des circonstances exceptionnelles et à une dispense éventuelle pour les femmes malades ou indisposées, c'est donc que soit elle date d'une époque où cette idée de dispense n'était pas encore admise, soit plus probablement que les milieux où cette tradition est née étaient hostiles à toute dispense accordée aux femmes, même sous certaines conditions. Il est significatif que parmi toutes les traditions ayant trait au hammâm compilées par Ibn Hanbal dans son Musnad, on n'en rencontre aucune qui fasse référence à cette idée de dispense pour les femmes, alors qu'il en est question pour les hommes. L'idée de dispense pour les femmes sous certaines conditions date sans aucun doute du siècle précédent, mais jusqu'au milieu du siècle suivant, comme le montre l'exemple de Ibn Hanbal, les ahl al-hadît n'étaient pas prêts à l'entériner. La principale raison de ce refus est la question de la nudité : une femme peut-elle se découvrir entièrement hors du domicile conjugal ? On peut relever que pour les adversaires de la fréquentation du hammâm par les femmes, peu importe qu'une femme se dénude devant des hommes ou devant d'autres femmes. Leur hostilité est donc avant tout dictée par leur engagement en faveur d'une police très stricte et sévère des mœurs : la promiscuité 
de corps nus dans un lieu public clos est une menace pour l'ordre religieux et moral.

Une autre tradition, tout en circonscrivant directement les bains à la région de Syrie (Shâm), voire à la ville de Hims (Emèse), énonce l'interdiction de la fréquentation du hammâm par les femmes sans faire référence non plus à nulle dispense pour un motif médical ou non. Aller au hammâm implique nécessairement se dévêtir ailleurs que chez soi ; pour une femme, cela revient à le faire en dehors du domicile conjugal, dans un lieu où elle n'est pas à l'abri des regards étrangers.

(ix) Un homme des Kinda a rapporté : Je suis allé voir ${ }^{c} \hat{A}$ 'isha ; un voile nous séparait. - De quel pays es-tu ? - De Kinda. - De quelle circonscription précise ? - De Hims. - Des gens de Hims qui permettent à leurs femmes de fréquenter le hammâm ? - Par Dieu, certes elles font bien cela ! - Si une musulmane ôte ses vêtements à l'extérieur du domicile conjugal, elle déchire le voile (sitr) qu'il y a entre elle et son Seigneur ! Si elles osent agir ainsi, elles porteront des robes larges et amples qui dévoileront la totalité de leur corps, tandis que d'autres femmes se précipiteront pour les décrire à des amoureux (habîb) ou des hommes odieux (baghîdh) (...) $\left.{ }^{60}\right)$.

Cette tradition, qui n'apparaît que dans la collection de ${ }^{\mathrm{c}} \mathrm{Abd}$ al-Razzâq est une version supplémentaire de celle qui suit. Outre plusieurs différences dans le texte même - la (ix) ne concerne pas que le hammâm -, dans la suivante (avec ses nombreuses variantes), l'homme de Kinda est remplacé par un groupe de femmes.

(x) « Des femmes de Syrie sont entrées chez ${ }^{\mathrm{c}} \hat{\mathrm{A}}$ 'isha. - D'où venezvous ?, leur demanda-t-elle. - De Syrie. - Vous êtes certainement de cette contrée (kûra) dont les femmes fréquentent les bains ? - Oui. - J'ai entendu le Messager de Dieu dire : Chaque fois qu'une femme se déshabille en-dehors de sa demeure, elle déchire ce qu'il y a entre elle et Dieu ${ }^{61}$, ou bien, selon une variante, "Chaque fois qu' une

60. cAbd al-Razzâq, op. cit., 293-4, nº 1131 . Cette tradition comporte une seconde partie qui ne concerne pas le hammâm.

61. Abû Dâwud, op. cit., 32, nº 4003 ; 'Abd al-Razzâq, op. cit., 294, $\mathrm{n}^{\circ} 1132$; Tayâlisî, Musnad, Beyrouth, s.d., 212, n 1518 ; Ibn Hanbal, op. cit., VI, 194, n 25 461, 25462 [173], 298, n 26358 [267] ; Dârimî, Sunan, Istamboul, 1992, II, 193, n 2654 et n 2655 ; Ibn Habîb, op. cit., 234, n 156 (dans cette variante, il y a ce fragment supplémentaire : «Craignez Dieu et ne 
femme ôtera ses habits en-dehors de la demeure de son époux, elle déchirera le voile (sitr) entre elle et Dieu ${ }^{62}$. Zuhrî, qui ne figure dans aucun isnâd précédent, rapportait sous une forme indirecte cette tradition en la résumant sous la forme de la défense pour les femmes de fréquenter le hammâm. ${ }^{63}$ Dans une autre version, ${ }^{\mathrm{c}} \hat{\mathrm{A}}$ 'isha dit à ses interlocutrices : J'ai entendu le Messager de Dieu dire : « Le hammâm est illicite pour les femmes de ma communauté ». Alors une des femmes présentes déclare: J'ai des filles que je coiffe en usant d'une boisson. - Quelle boisson, demande ' ${ }^{\mathrm{A}}$ 'isha ? - Du vin ! - Si tu avais l'âme pure, pourrais-tu te servir du sang du cochon pour te coiffer ? Non ! - Eh ! bien ! c'est pareil ! ${ }^{64}$. Dans une dernière version de cette tradition, le dialogue a lieu entre Umm Salama, une autre épouse du Prophète, et ses visiteuses : «- Êtes-vous de celles qui fréquentent le hammâm ? - Y a-t-il un mal dans cela ? - J'ai entendu le Messager de Dieu dire: Chaque fois qu'une femme ôte ses vêtements hors de chez elle, Dieu déchire le voile qui est sur elle » ${ }^{65}$.

Il y a une contradiction entre cette série de traditions et la tradition (vii), puisque dans cette dernière ${ }^{c} \hat{A}$ 'isha est présentée comme favorable à la fréquentation du hammâm par les femmes. Par ailleurs la tradition (ix) ne rapporte pas les propos de Muhammad, mais c'est $^{c} \hat{A}$ 'isha qui émet sa propre opinion.

Toutes ces traditions partagent un trait commun : le hammâm met en cause le rapport du corps féminin, plutôt d'ailleurs celui de l'épouse, à Dieu. La femme mariée doit demeurer parfaitement chaste ; cela veut dire notamment, réserver ses charmes à son seul époux. Cette situation est décrite grâce à la métaphore du voile (sitr), qui s'interpose entre Dieu et toute femme mariée ; quand celle-ci se

déchirez pas le voile (sitr) grâce auquel Dieu vous a protégées ! ) ; Hâkim, Mustadrak, IV, 321, n 7780 et 7781 ; Bayhaqî, op. cit,. 157-8, n 7771 ; Baghawî, Sharh al-sunna, éd. Arnâ'ût, Beyrouth, 1983, XI, 123, n 3210. Une version compilée par Ibn Hanbal (op. cit., VI, 221, nº 25683 [199]) ne comporte que la seule maxime finale. Il n'y a rien d'étonnant dans le fait. De nombreux hadiths ont cette forme : une anecdote est suivie de l'énoncé d'une règle. Mais les deux éléments peuvent exister indépendamment l'un de l'autre : on peut avoir affaire à la seule anecdote, ou au seul énoncé de la règle.

62. Ibn Mâja, op. cit., IV, 225, 3750 ; Tirmidî, op. cit., 182, n 2803.

63. ' Abd al-Razzâq, op. cit., 293, n 1130.

64. Hâkim, op. cit., 322, $\mathrm{n}^{\circ} 7784$.

65. Bayhaqî, op. cit., 158-9, n 7774 ; Hâkim, op. cit., 321, n 7 782. Autre version, partiellement incomplète, chez Ibn Hanbal, Tabarânî et Abû Yaclâ (Nûr al-dîn al-Haytamî, op. cit., 277). 
dévêt dans le hammâm, c'est-à-dire hors de chez elle, elle porte atteinte à ce voile. C'est comme si elle arborait sa nudité face à Dieu Lui-même.

Un des noms qui revient le plus souvent dans les chaînes de transmission de ce texte est Mansûr. Il s'agit sans aucun doute de Ibn al-Muctamir (m. 132/749), qui se rattache au groupe des ahl alhadît, adversaire des Mutazilites et des ahl al-ra'y. On le présente comme particulièrement pieux et voué au culte de Dieu (mutacabbid) ; il fut contraint en vain par les autorités de l'époque à adhérer à la doctrine muctazilite du libre-arbitre (qadar). Malgré des sympathies chiites, sans excès ${ }^{66}$, il est connu comme une des plus éminentes autorités en matière de hadith parmi les hommes de religion de Kûfa ${ }^{67}$.

On le voit, la majeure partie des traditions hostiles à la fréquentation des bains publics par les femmes se trouvent dans les collections de Ibn Hanbal (m. 241/855), de son élève Abû Dâwûd (m. 275/888) ou de ses disciples Tirmidî (m. 279/892) et Tabarânî (m. 360/970) ${ }^{68}$. Sur six traditions, quatre sont présentes dans la compilation de Ibn Hanbal ${ }^{69}$. En revanche, aucune tradition favorable, même sous conditions, à la fréquentation du bain par les femmes n'est présente dans cette compilation. ${ }^{70} \mathrm{Il}$ n'est donc pas exagéré de voir en Ibn Hanbal un des juristes les plus hostiles au hammâm, en particulier à

66. Peut-être défendait-il simplement ${ }^{\mathrm{c}}$ Alî, dans un milieu qui, par réaction au chiisme naissant, lui était souvent défavorable ? Aussi pouvait-il être accusé de tashayy $\hat{u}^{c}$.

67. Op. cit., IV, 159-60.

68. Sur les relations de ces traditionnistes à Ibn Hanbal et à sa pensée, voir Henri Laoust, « Le hanbalisme sous le Califat de Bagdad (241/855-656/1258) », Revue des Études Islamiques, 1959, XXVII, 77, 78 et 89-90.

69. Cette compilation, peu juridique, a été mise en forme par le fils de Ibn Hanbal, qui n'a pas manqué « en toute bonne foi » d'ajouter plusieurs centaines de traditions à l'œuvre de son père. Sur cette importante compilation, voir Christopher Melchert, «The Musnad of Ahmad ibn Hanbal : how it was composed and what distinguishes it from the Six Books », Der Islam, 2005, Bd 82, 32-51.

70. De nombreux compilateurs de traditions prophétiques prétendent, à l'instar d'Ibn Hanbal, n'être guidés que par le souci objectif de recueillir les paroles attribuées à Muhammad. Cependant on remarque comme dans le cas présent que leur travail de compilation est souvent déterminé par leurs positions théologiques, juridiques et morales. 
sa fréquentation par les femmes. C'est pour cette raison que l'école juridique qui se réclamera de lui conservera en partie cette hostilité. - Cas de dispense.

La tradition qui suit prend la forme d'une prophétie; en même temps elle énonce la règle médiane, qui va être acceptée par toutes les écoles ${ }^{71}$.

(xi) Le Messager de Dieu a dit : « Vous conquerrez des terres étrangères, où vous trouverez des maisons qu'on appelle des bains (hammâmât). L'homme ne devra y pénétrer que revêtu d'un pagne (izâr) ; quant aux femmes vous les empêcherez d'y entrer, sauf celle qui est malade et la parturiente (nufas $\left.\hat{a}^{\prime}\right){ }^{72}$.

(xii) Umm Kultûm a rapporté : cÂ'isha m'a commandé de l'épiler, puis ensuite de lui appliquer du henné de la tête aux pieds, dans le hammâm, à cause d'une éruption de boutons (min hasiba kânat bihâa $)^{73}$. $-\mathrm{Ne}$ défendais-tu pas aux femmes de fréquenter le hammâm ? - Je suis malade (saqîma). Même actuellement, je défends à toute femme qui n'est pas malade d'aller au hammâm ${ }^{74}$.

La tradition (xi) repose sur un présupposé : il n’y a pas de bains dans le Hijâz. Comme beaucoup d'autres traditions, elle se présente comme une prévision : les armées musulmanes vont conquérir les

71. Les juristes ajouteront comme cas de dispense la sortie de la période menstruelle.

72. Ibn Mâja, op. cit., 224, n 3748 ; Abû Dâwud, op. cit., 32-3, nº 4004 ; variante chez cAbd al-Razzâq, op. cit., 290-1, n 1 119; Ibn Habîb, op. cit., 232, $n^{\circ} 154$; Bayhaqî, op. cit., 159, nº 7 775. Nûr al-dîn al-Haytamî, op. cit., 278 : d'après Tabarânî : "Vous ferez la conquête de terres lointaines (ufuq) dans lesquelles il y aura des maisons appelées hammâm. Leur fréquentation est interdite à ma communauté. Ils dirent : - Ô Messager de Dieu ! il guérit des maux (wasab) et fait disparaître la saleté (daran). - Il est donc licite aux mâles ( $\underline{d} u k \hat{u} r)$ de ma communauté qui portent un pagne et défendu aux femmes (inât $\underline{t}$ ». Chez Ibn Huzayma, il est question d'entrée dans l'eau et non dans le hammâm (duhûl al-mâ') : "Le Prophète a défendu d'entrer dans l'eau sans pagne (mi'zar)» (Sahîh, Beyrouth, 1992, I, 124, n 187). S'agit-il d'entrer dans un bassin ou même dans un cours d'eau?

73. C'est ainsi qu'il faut lire et non min hisn kâna bihâ, ce qui ne veut rien dire.

74. ' ${ }^{\mathrm{A}}$ bd al-Razzâq, op. cit., 295-6, n 1135 ; variante dans Ibn Habîb, op. cit., 232-3. Le mal dont il est question est dit hasf, qui selon Ibn Manzûr (Lisân, notice tîb) ferait que la peau pèle (Ibn Habîb, op. cit., 233, note 6). Selon Alexandre de Biberstein Kazimirski, hasaf est une "gale sèche » (Dictionnaire arabe-français, Paris, 1860, I, 442 ${ }^{\mathrm{a}}$ ). 
villes romanisées d'Orient et y découvrir pour la première fois le hammâm. Muhammad, qui annonce une découverte future, en connaît l'utilité et la nature dangereuse, à la différence de ses fidèles. Cependant la tradition ne se limite pas à cela : il y édicte au futur deux règles. D'une part, les hommes ne devront y pénétrer que revêtus d'un pagne ; d'autre part, il faudra défendre aux femmes d'y aller, à l'exception des malades et des parturientes. Cette tradition apparaît ainsi comme la tentative de donner une autorité indubitable à ces deux règles en les mettant a posteriori sur le compte de Muhammad lui-même. Ce faisant, on a introduit une brèche dans l'interdiction faite aux femmes de fréquenter le bain public au nom de la santé et de la coutume ${ }^{75}$. Plus tard, les juristes ajouteront d'autres motifs de dispense.

De ces différentes traditions, on peut tirer la conclusion suivante. $\mathrm{Au}$ milieu du $\mathrm{III}^{\mathrm{e}} / \mathrm{IX}^{\mathrm{e}}$ siècle, la doctrine au sujet du hammâm était que si sa fréquentation était permise aux hommes, à condition qu'ils portent un pagne, elle était interdite aux femmes sauf en cas de maladie ou un accouchement. Les textes insistent notamment sur deux règles : obligation pour les hommes de se couvrir, interdiction nette pour les femmes. L'enjeu de cette attitude complexe est le problème de la nudité. En effet, si le hammâm a suscité de telles résistances, c'est parce qu'il met en cause une règle fondamentale attestée dans tous les corpus celle - valable pour les hommes comme pour les femmes - de ne point dévoiler sa nudité devant des étrangers, y compris des parents au degré non prohibé. On peut suggérer que la doctrine a connu trois étapes : d'abord une interdiction totale aux hommes comme aux femmes; ensuite la permission accordée aux hommes sous réserve du port du pagne avec maintien de l'interdiction pour les femmes; enfin dispense accordée aux femmes malades, indisposées ou parturientes.

75. Il est de règle, selon la coutume, qu'après le retour de couches, la femme se rende au bain, comme pour se purifier de toutes les conséquences de l'accouchement, et comme dans le cadre d'un rite de passage, qui marque son retour à un état ordinaire, pour ne pas dire profane. La référence aux couches comme dispense pour fréquenter le hammâm est l'expression de cette coutume. 
- Des traditions hostiles au hammâm.

Les traditions hostiles à la fréquentation du hammâm par les femmes sont nombreuses. Même quand elles n'ont pas été recueillies dans les grandes compilations, elles ont continué à circuler et à nourrir la prédication des oulémas les plus rigoristes. Dans un important ouvrage, où il a recueilli de nombreuses traditions ayant trait aux femmes, le mâlikite andalou Ibn Habîb (m. 238/852) en a retenu plusieurs ayant trait au hammâm. ${ }^{76}$ À côté de certaines connues, et que nous avons déjà rencontrées, d'autres sont uniques et méritent évidemment d'être examinées de près. Après les traditions que nous avons déjà rencontrées « Vous conquerrez des terres étrangères, etc. » via ${ }^{\mathrm{c} A b d}$ Allâh b. ${ }^{\mathrm{c} A m r}$ b. al-c ${ }^{-\mathrm{A} s}$ (m. vers $\left.63 / 683\right)^{77}$; «Celui qui croit en Dieu et au Jour dernier, etc. » via al-Munkadir b. Muhammad (m. 180/796), via son père [Muhammad b. al-Munkadir] (m. 130/ 747) ; la missive adressée par le second Calife à son gouverneur de Syrie.; et le fameux hadith sur la visite de Syriennes à ' $\hat{A}$ 'isha via Sâlim b. Abî al-Jacd (m. 97/715) ${ }^{78}$, Ibn Habîb a recueilli quatre traditions qui ne figurent pas dans les collections connues.

La première tradition est favorable à la fréquentation du hammâm par les femmes si elles respectent les règles de la décence :

«Si l'une d'entre nous entre au bain vêtue d'une chemise dépourvue de manches (qarqal) ? - Qu'est-ce que cela ? - Elle est semblable à la chemise dite $\operatorname{dir}^{r} a^{79}$. - Il n'y a donc pas de mal».

76. Cet ouvrage a été édité sous le titre de Kitâb adab al-nisâ' par Abd alMagid Turki en 1992, avec une riche introduction. La réputation d'Ibn Habîb dans le domaine du hadîth était controversée, comme en témoigne ce propos cité par Qâdhî 'Iyâdh : «Il n'avait aucune compétence dans la science du hadîth et ne savait pas distinguer celui qui était authentique de celui qui était faible » (lam yakun lahucilm bi-l-hadît wa lâ macrifa bi-sahîhihi min saqûmihi) (Tartîb al-madârik wa taqrîb al-masâlik, Beyrouth, 1998, I, 382). Voir quelques indications à son sujet dans Isabel Fierro, «The introduction of hadîth in alAndalus », Der Islam, 1989, LXVI, n 1, 68-93, notamment p. 75-7.

77. Op. cit., $232, \mathrm{n}^{\circ} 154$.

78. Il appartiendrait à la catégorie des $m u^{c}$ ammarûn selon A. Turki (Ibn Habîb, op. cit., index nominum).

79. Selon Kazimirski, $\operatorname{dir}^{c}$ est une chemise de femme (op. cit., I, 689 ${ }^{\text {b). }}$ Cf. aussi Ibn al-Atîr, Al-nihâya fî gharîb al-hadît wa-l-ațâr, Beyrouth, s.d., II, 114 et Reinhart Dozy, Dictionnaire détaillée des noms des vêtements chez les Arabes, Beyrouth, 1845, réédition, s.d., p. 176-7 (« le mot $d_{i r}{ }^{c}$ ne s'applique qu'à une chemise de femme »). 
Ce texte a été transmis par Layt b. Sacd (m. 175/791), un juriste égyptien, contemporain de Mâlik.

Il n'en est pas de même des trois traditions suivantes, qui sont extrêmement sévères et proscrivent la fréquentation du hammâm par les femmes. Dans une tradition, qui appartient certainement au même ensemble que les traditions sur les Syriennes rendant visite à 'Â' isha, parce qu'elle partage avec elles un certain nombre de traits communs, c'est à un véritable prône que nous avons droit. On y reconnaît également le hadith examiné précédemment qui commence par la formule stéréotypée «Celui d'entre vous qui croit en Dieu et au Jour Dernier ». L'épouse de Muhammad n'y ménage ni les femmes ni les hommes, qu'elle réprimande également :

«Un jour ${ }^{\mathrm{C}} \hat{\mathrm{A}}$ 'isha déclara à des femmes réunies chez elle : Ô ! femmes ! craignez Dieu, votre Seigneur ! Soyez zélées dans vos ablutions, faites vos prières et acquittez-vous de l'impôt canonique (zakât)... ! Obéissez à vos époux, que vous le vouliez ou non! Et gare aux bains publics ! J'ai entendu le Messager de Dieu dire : Chaque fois qu' une femme entre dans un bain public, Satan pose la main sur son bas-ventre (qubul). Selon ce qu'il désire, il l'aborde de face ou de dos. Fuyez le bain public ; il est une des maisons des mécréants (bayt min buyût al-kuffâr) et une des entrées de la Géhenne (bâb min abwâb jahannam). Ô! vous les hommes ${ }^{80}$ ! Celui d'entre vous qui croit en Dieu et au Jour dernier ne doit pas permettre à son épouse légitime (halîla) de se rendre au bain public ! Les hommes ont une éminence sur les femmes (al-rijâl qawwâmûna ${ }^{c}$ alâ al-nisấ ${ }^{81}$ ! Retenez vos épouses et ne faites de reproches qu'à vous-mêmes! Apprenez-leur le Qur'ân et commandez-leur de louer Dieu le matin et le soir (tarafay) ${ }^{82}$ ! Ne les invitez pas à sortir de leurs demeures! $»^{83}$.

Cette tradition en faveur de la plus grande rigueur et de la claustration des femmes dans le domicile conjugal a été transmise par 'Atâ' al-Hurâsânî (m. 135/752). On peut remarquer qu'elle constitue une injonction à obéir aux époux. Le lien du hammâm avec Satan va dans le sens de ce que nous avons déjà écrit - il n'y a rien de surprenant de ce point de vue -, par contre la référence à l'Enfer

80. Ce dernier fragment est surprenant car au début du texte il était question d'un public exclusivement féminin. Ne s'agit-il pas d'une interpolation ?

81. Il s'agit d'une citation coranique $(2,228)$.

82. C'est-à-dire aux deux extrémités de la journée.

83. Op. cit., 235. 
mérite que l'on s'y arrête. Le hammâm est défini dans ce texte comme « une des entrées de l'Enfer ». Or on l'a déjà indiqué précédemment, de nombreux textes, modérément favorables au hammâm font également ce lien, mais dans un sens complètement différent : alors qu'ici, la référence à l'Enfer, qui renforce celle à Satan, est destinée à détourner les femmes de la fréquentation du hammâm, dans les autres textes, la salle chaude du bain doit être reçue par le baigneur comme une image de ce qui attend le pécheur après la mort. Le hammâm est « une des entrées de l'Enfer » à cause des péchés qui s'y commettent.

La tradition suivante reprend plus brièvement et en des termes différents ce précédent propos :

«On a interrogé c $\hat{A}$ 'isha au sujet de la fréquentation du hammâm par les femmes: C'est un voile (hijâb) qui ne protège pas, une eau qui ne purifie pas, une des portes du Feu ( $\left(a^{c} \hat{i} r\right)$, une des maisons des associationnistes et une des aires de jeu des démons (shayâtîn). Quand une femme entre au hammâm, Satan pose sa main sur ses parties (qubul). Selon son désir, elle montrera son devant ou son derrière. Elle a ajouté : J'ai entendu le Messager de Dieu dire : "CUtmân a honte de Dieu et moi aussi j'ai honte! Qui donc a honte de Dieu ?" Elle a ajouté : Qu'en est-il de la femme entièrement nue, qui n'a point honte de Dieu ? $»^{84}$.

La dernière tradition, mise sur le compte de Muhammad et non plus de son épouse, menace les époux qui feraient preuve de trop de libéralisme avec leurs épouses :

« Dieu plongera dans le feu la tête en avant l'homme qui aura obéi à sa femme au sujet de quatre choses: les vêtements fins, les bains, les séances de pleurs (manâhât) et les mariages ( ${ }^{c}$ arâ'is) $»^{85}$.

Le transmetteur de ce texte est le Tunisien cAlî b. Ziyâd (m. 183/ 799), qui était un disciple de Mâlik.

De tels textes, d'une dureté incomparable pour le hammâm, devaient dissuader tous les fidèles zélés ou scrupuleux, de même qu'ils devaient culpabiliser les plus tièdes. Ce type de texte ne relève pas du genre normatif au sens courant, dans la mesure où leur but n'est pas de réglementer, mais il s'agit de brandir la menace du Feu éternel pour obtenir l'adhésion, voire la soumission de ceux auxquels

84. Op. cit., 235-6.

85. Ibn Habîb, op. cit., 212, n 120. 
ils s'adressent. Il est significatif tout de même qu'aucun de ces textes n'aient été retenus dans aucune compilation canonique. La raison en est qu'ils apparaissaient comme excessifs et aussi probablement irréalistes. Tant les autorités politiques que les hommes de religion n'ont jamais cru qu'il était possible d'empêcher les femmes de fréquenter les bains publics; or ces textes militaient dans ce sens.

\section{LA TRADITION IMÂMITE}

De manière générale, on observe que les sources imâmites sont beaucoup plus favorables au bain public que les sources sunnites. Le meilleur témoignage est l'anecdote suivante qui oppose dans un face-à-face, qui relève moins de l'histoire que de la méta-histoire, cUmar (m. 23/644), le second Calife, à cAlî b. Abî Tâlib (m. 40/661), son adversaire, quatrième Calife et $\mathrm{I}^{\mathrm{er}}$ imâm chiite. On raconte qu' un jour ils se sont rendus ensemble au bain. Le premier eut cette réflexion : «La pire des maisons c'est le hammâm : on y peine beaucoup plus et la pudeur y décroît ». Le second lui répondit par celleci : «La meilleure des maisons c'est le hammâm : il fait disparaître le mal (ad̂a) et rappelle le Feu éternel $\gg .{ }^{86}$ Par là, on voit très clairement que les imâmites ne font preuve d'aucune hostilité envers le hammâm. Ils vont même jusqu'à attribuer la position opposée au sunnisme, afin de s'en démarquer.

- Cependant, là aussi un des grands problèmes tient à la nudité. On fait dire à cAlî : "Quand l'un de vous se dénude, Satan porte sur lui son regard et le désire ardemment. Aussi couvrez-vous ! ${ }^{87}$. « Il a défendu à l'homme d'entrer dans l'eau [du fleuve ?] si ce n'est vêtu d'un pagne ${ }^{88}$. On lui fait dire également : «Il y a deux parties

86. Tûsî, Tahdîhb al-ahkâm, Beyrouth, 1981, I, 377, n $^{\circ} 1166$. Des propos sur le hammâm, parfois très durs, sont mis chez les sunnites sur le compte de 'Alî. Mais il s'agit d'une autre figure, relativement différente, voire antinomique avec celle que vénèrent les chiites.

87. Tûsî, op. cit., $373, \mathrm{n}^{\circ} 1144$.

88. Tûsî, op . cit., $373-4, \mathrm{n}^{\circ} 1145$. Cf. la tradition n ${ }^{\circ} 187$ compilée par Ibn Huzayma (ci-dessus note 66). 
honteuses : le devant et le derrière. Cette dernière est protégée par les fesses. Si tu caches ton membre et tes deux testicules, alors tu as caché ta nudité ${ }^{89}$. ${ }^{\mathrm{c} A l i ̂ ~ a d m e t t a i t ~ l a ~ r e ́ c i t a t i o n ~ d u ~ C o r a n ~ d a n s ~ l e ~}$ hammâm de même que la copulation ${ }^{90}$. Interrogé au sujet de la récitation du Coran dans le hammâm, un imâm disait à son interlocuteur : "Si tu portes un pagne, récite même la totalité du Coran si tu le désires ! ${ }^{91}$.

- Jacfar (m. 148/765), VI e imâm, répondait ainsi à un fidèle qui voulait savoir s'il était permis à l'homme de se laver nu : « Si personne n'est témoin, il n'y a aucun mal ${ }^{92}$. On fait dire au même : «L'homme ne devra pas poser les yeux sur les parties de son frère ${ }^{93}$. Un témoin rapporte l'avoir croisé nu, couvrant seulement son bas-ventre. Il aurait alors dit : «La cuisse n'entre pas dans la nudité » (inna al-fahd laysat min al-cawra) ${ }^{94}$. Jusqu'ici ces textes n'opposent pas réellement les conceptions imâmites à celles soutenues par les sunnites. Cependant, selon certaines traditions, Ja'far interprétait dans un sens allégorique le propos, attribué par les sunnites à Muhammad : "Il est illicite aux croyants de poser les yeux sur les parties du croyant ». « On ne doit pas comprendre ce propos dans le sens qu'on lui donne [habituellement]. La nudité du croyant c'est l'erreur qu'il a commise, ou le propos inconvenant qu'il a tenu, et qui sera retenu et dont on se servirait un jour pour l'insulter». «-S'agit-il, dit un interlocuteur de l'imâm, du bas-ventre ? - Ce n'est pas l'endroit que tu désignes, c'est que tu dévoiles ses secrets. » « Ce n'est pas qu'il se dénude et que tu le vois ainsi, mais que tu le grondes ou que tu l'injuries. ${ }^{95}$

89. Tûsî, op. cit., n 1151 .

90. Tûsî, op. cit., $\mathrm{n}^{\circ} 1155$.

91. Tûsî, op. cit., 377, $\mathrm{n}^{\circ} 1$ 165. Voir à ce sujet Benkheira, op. cit., 417-9.

92. Tûsî, op. cit., $\mathrm{n}^{\circ} 1$ 148. Dans le sunnisme, il vaut mieux ne jamais être nu même quand on est entièrement seul, car on offense ainsi Dieu, lequel voit tout, à tout moment.

93. Tûsî, op. cit., $\mathrm{n}^{\circ} 1149$.

94. Tûsî, op. cit., $\mathrm{n}^{\circ} 1150$. Il y a là une référence évidente à une question casuistique importante : un homme peut-il découvrir ou non sa cuisse ?

95. Tûsî, op. cit., 375, nº 1152 à 1154 . 
- Les imâms chiites usaient de pâte à épiler sans réticence et avec même un certain enthousiasme. C'était le cas de ${ }^{c}$ Alî. «Un témoin rapporte : J'étais dans la salle du milieu [intermédiaire entre la salle froide et la salle chaude] quand entra ${ }^{\mathrm{c}}$ Alî Abû al-Hasan [le quatrième Calife]. Il avait mis de la pâte à épiler et portait pardessus un pagne. Il a dit : Que la paix soit sur vous. J'ai répondu à son salut et je me suis hâté ; je suis entré dans la salle dans laquelle se trouve le bassin pour me laver et sortir ${ }^{96}$. Le VI imâm y est encore plus nettement favorable. Un fidèle vient voir $\mathrm{Ja}^{\mathrm{c}}$ far, qui est au hammâm. Il s'y rend alors pour le rencontrer; il le trouve en train d'appliquer sur son corps de la pâte à épiler. Il lui parle de son affaire. «- Tu ne veux pas t'épiler ? lui dit l'imâm. - Je l'ai déjà fait avant-hier. - Applique-toi de la pâte à épiler, elle est purificatrice ! ${ }^{97}$. Si l'on n'a pas les moyens pour acquérir de la pâte pour s'épiler, on ne doit pas hésiter à s'endetter : «La règle (sunna) est d'user de la pâte à épiler tous les quinze jours, fait-on dire à l'imâm $\mathrm{Ja}^{\mathrm{c}}$ far. Si au bout de vingt jours, tu n'as pas d'argent pour le faire, tu peux emprunter à la grâce de Dieu $!{ }^{98}{ }^{98}$. Un fidèle se plaint à lui au sujet du coût de revient de cette pâte. En effet, sur le chemin pour La Mecque, au lieu de fabriquer la pâte à épiler avec des déchets (nuhâla), il la fabrique avec de la farine (daqîq). L'imâm lui demande : - As-tu peur du gaspillage ${ }^{99}$ ? - Oui. - Il n'y a pas de gaspillage quand il s'agit d'améliorer l'apparence du corps (badan). $\mathrm{Si}$ on te commande de t'enduire avec de la moelle mélangée avec de l'huile, frotte-toi avec ${ }^{100}$. Le gaspillage c'est ce qui entraine la ruine et nuit au corps en même temps » ${ }^{101}$. Jacfar fait également l'éloge du henné : il chasse selon lui l'odeur de la transpiration ( sahak), humidifie le visage, donne une bonne haleine (naha) et une belle progéniture ! «Celui qui, après s'être enduit de henné de la tête

96. Tûsî, op. cit., 374, n 1147.

97. Tûsî, op. cit., $\mathrm{n}^{\circ} 1156$.

98. Tûsî, op cit., 375-6, n 1157.

99. Le gaspillage est une faute religieuse majeure. Il forme un couple avec l'avarice.

100. L'huile est un bien plus coûteux que la farine, donc plus ruineux.

101. Tûsî, op. cit., 376, $\mathrm{n}^{\circ} 1160$. 
au pied, se masse, ne connaîtra plus jamais la pauvreté »102. Quant à Abû Jacfar le Second (m. 220/835), IX imâm, on l'a aperçu un jour à la sortie du hammâm, couleur de henné de la tête au pied, « semblable à une rose » dit la tradition ${ }^{103}$. Un fidèle écrit un jour à l'imâm Abû al-Hasan pour lui demander s'il était permis de se servir de pâte épilatoire tout en étant en état d'impureté majeure (junb). L'imâm lui écrit : "La pâte épilatoire augmente la propreté de celui qui est dans cet état. Cependant celui qui a mis du henné, homme ou femme, devra s'abstenir de relations sexuelles » ${ }^{104}$.

\section{Promouvoir la décence}

Le problème central posé par le hammâm à l'islâm et à ses représentants est celui de la nudité des corps. Il en était tout autrement pour les Grecs et les Romains. L'islâm émerge à la fin de l'Antiquité tardive, à une époque et dans une région du monde labourées par de nombreuses religions et conceptions philosophiques, comme le christianisme, le gnosticisme, le stoïcisme ou le platonisme, qui tendent toutes à arrimer étroitement l'attitude morale à la domination sur le corps physique. Toute exaltation de ce dernier et toute faiblesse à son égard sont perçues comme coupables. L'individu qui recherche la sagesse comme celui qui recherche le salut s'accordent pour reconnaître que la répression des appétits physiques en général (jeûne, chasteté, pauvreté volontaire, veillées nocturnes, etc.) est l'unique voie qui peut mener à ce résultat. Cependant, en islâm, le corps humain ne sera pas tenu pour laid ${ }^{105}$, tout en étant considéré comme honteux. L'état d'humain ce n'est pas d'exhiber son corps nu - comme les bêtes - mais au contraire de porter des vêtements. La

102. Tûsî, op. cit., 376, n 1161. Fasawî (m. 277/890) rapporte que Hasan et Husayn, les second et troisième imâms usaient fréquemment de henné dans le hammâm (Kitâb al-macrifa wa-l-târîh, Beyrouth, 1999, II, 112 et 113).

103. Tûsî, op. cit., 377.

104. Lâ yujâmic u al-rajulu muhtadhib ${ }^{\text {an }}$ wa lâ tujâmicu imra'a $a^{\text {tun }}$ muhtadhibatan (Tûsî, op. cit., 377, n $^{\circ}$ 1164).

105. Dans le Coran, l'homme apparait plutôt comme une belle créature $(\mathbf{1 5}, 29 ; \mathbf{3 2}, 9 ; \mathbf{4 0}, 64 ; \mathbf{7 5}, 38 ; \mathbf{7 6}, 28 ; \mathbf{8 2}, \mathbf{7})$. 
bête sert de ce point de vue à représenter l'anti-humain ${ }^{106}$. C'est pour cela que les juristes seront amenés à mettre en doute la bonne moralité, voire la raison, de celui qui se dénude en présence d'autrui, assimilé de ce point de vue à un animal. ${ }^{107}$

La nudité n'a pas que des conséquences légales. Se mettre nu est, comme la possession chez soi d'images ou de chiens, antinomique avec la présence de l'ange qui veille sur chaque croyant. Cela donc porte malheur. En chassant ce gardien, le croyant devient une proie plus facile pour les démons. «Hasan b. 'Ubayd Allâh raconte : Abû Sâdiq m'a vu aller au hammâm. Il m'a dit : As-tu avec toi un pagne ? cAlî b. Abî Tâlib disait : "Celui qui découvre sa nudité, l'Ange s'éloignera de lui » ${ }^{108}$. Une tradition prophétique, qui n'est pas tenue pour vraie, va même plus loin : «Celui qui fréquente le hammâm sans porter de pagne est maudit par Dieu et par les anges ${ }^{109}$. Dans tous les milieux, y compris profanes, circulent des formules qui témoignent d'une certaine hostilité à l'égard du bain public. Le grand écrivain abbâside, Abû Hayyân al-Tawhîdî a rapporté dans un de ses célèbres ouvrages un texte qui a de nombreuses versions, la plupart du temps présentées comme des traditions, prophétiques ou non : «Le hammâm est la pire (bi's) des demeures, il chasse la pudeur (hayâ') et découvre la nudité ( $\left.{ }^{c} a w r a\right) » 110$.

\section{L'intervention des autorités politiques}

C'est sans aucun doute sous l'influence de la tendance puritaine parmi les oulémas que le pouvoir califal va intervenir dans la gestion des bains publics, pour les soumettre à des règles conformes aux

106. La chèvre est décriée parce que ses parties seraient découvertes tandis que la brebis est louangée pour la raison contraire (Ibn Qutayba, ${ }^{c} U y u \hat{n}$ al-ahbâr, Beyrouth, 1986, I, 76).

107. Voir plus loin, le paragraphe qui a trait au concept de ${ }^{c}$ adâla. D'autres comportements susceptibles d'en représenter la perte : marcher nue tête ou pieds nus, manger dans la rue, etc.

108. Ibn Abî Shayba, Al-Musannaf, éd. Shâhîn, Beyrouth, 1995, I, 104, $\mathrm{n}^{\circ} 1174$.

109. Ibn Hajar al-Haytamî, op. cit., 279.

110. Tawhîdî, Al-imtấ $\hat{~}^{c}$ wa-l-mu'ânasa, éd. Amîn, Beyrouth, 1986, II, 197. 
idéaux de pudeur et de décence dont ils veulent croire qu'ils sont au cœur de la morale de la nouvelle religion. Cet interventionnisme moralisateur a été mis sur le compte principalement de deux califes durant la période primitive.

- La politique de cUmar I (m. 23/644).

cUmar b. al-Hattâb est présenté comme le premier calife qui a manifesté par ses décisions le souci de la bonne moralité des baigneurs et des baigneuses. ${ }^{111} \mathrm{La}$ tradition sunnite n'hésite pas à mettre sur son compte la règle du pagne pour les hommes. Il aurait envoyé une directive à ses représentants dans les provinces : «Que nul n'entre au hammâm s'il n'est revêtu d'un pagne »112. Cette instruction est devenue probablement par la suite une tradition prophétique, aux nombreuses versions (voir plus haut) : « Le Messager de Dieu a défendu de pénétrer dans l'eau [du bassin ou de la rivière ?] sans un pagne ${ }^{113}$. Il aurait envoyé une missive dans ce sens à cAbd Allâh b. Qays Abû Mûsâ al-Ash'arî (m. 42 ou 44/664 ou 666), le gouverneur de Basra, lui disant : "N'entrez dans le hammâm que couverts d'un pagne et que deux [hommes] ne doivent pas se laver du même bassin (hawdh) ${ }^{114}$. La seconde partie de l'instruction concerne l'immersion de plusieurs hommes dans un même bassin : il est vraisemblable qu'à une époque très ancienne, les habitudes héritées des Romains - les Byzantins avaient interdit uniquement les bains mixtes entre hommes et femmes - étaient demeurées vivantes et qu'il a fallu que les autorités les combattent. On prête également à cUmar l'interdiction de prononcer le nom de Dieu dans le hammâm. Dans une autre version de son instruction sur les règles à observer à l'intérieur du hammâm, il aurait ajouté : «On n'y prononcera pas le nom de Dieu avant d'en être sorti ${ }^{115}$.

111. ${ }^{c}$ Abd Allâh b. al-Mubârak (m. 181/797) lui attribue même un propos très hostile au hammâm (Kitâb al-zuhd, éd. al-Aczamî, Beyrouth, 1998, 235, $\mathrm{n}^{\circ} 759$ ).

112. Ibn Abî Shayba, op. cit., $\mathrm{n}^{\circ} 1175$.

113. Abû Yaclâ al-Mawsilî, op. cit., II, 200, $\mathrm{n}^{\circ}$ 1801; Hâkim, op. cit., I, $267, \mathrm{n}^{\circ} 581$.

114. ' Abd al-Razzâq, op. cit., 291, n 1120 ; Muttaqî, op. cit., IX, 244, $\mathrm{n}^{\circ} 27412$ et 27417.

115. ' Abd al-Razzâq, op. cit., $\mathrm{n}^{\circ} 1121$; Muttaqî, op. cit. 
Au sujet de la fréquentation des bains par les femmes, on lui prête deux politiques contradictoires. Tantôt, on fait de lui un partisan de l'interdiction totale du bain aux femmes. Dans une missive dont le destinataire était Abû cUbayda b. al-Jarrâh (m. 18/640), gouverneur de Syrie, il aurait écrit : «Il m'est parvenu que parmi les musulmanes [de Syrie], certaines vont au hammâm. Défends-le leur !». Pourtant son destinataire ne l'interprète pas dans un sens prohibitionniste ; il prône le point de vue selon lequel les femmes doivent avoir une raison valable pour se rendre au hammâm. Après une lecture publique du texte du message du Calife, Abû cUbayda b. al-Jarrâh s'écria : « Ô ! Seigneur ! chaque fois qu'une femme va au hammâm sans souffrir d'aucun mal (min ghayr cilla wa lâ saqam), recherchant seulement la blancheur du visage, noircis-le le jour où $\mathrm{Tu}$ blanchiras les visages ! ${ }^{116}$. Si le fait est exact, cela voudrait dire que dès cette époque ancienne, on cherche à limiter la liberté des femmes à aller au hammâm. Le plus souvent on fait de 'Umar I l'adepte, voire le promoteur de cette politique. Il aurait donné l'ordre aux commandants de ses armées « de ne permettre à aucun homme d'entrer dans le hammâm sans pagne, ni à aucune femme excepté celle qui souffrait d'un mal » ${ }^{117}$. On notera avec intérêt que ${ }^{c}$ Umar I ne cherche à justifier sa politique par nul propos prophétique. Dans une autre version, il aurait ajouté : «Apprenez à vos femmes la sourate al$N \hat{u} r^{118} \gg^{119}$.

Il semble également avoir été préoccupé par la fréquentation des bains par les non musulmanes en compagnie des musulmanes. Il aurait dans cette perspective prescrit une politique de ségrégation stricte. Selon un récit, c'était le sens de sa lettre à Abû cUbayda b. al-Jarrâh (m. 18/640), gouverneur de Syrie : « On m’a informé que des musulmanes, [vivant dans la région qui est sous ton autorité], fréquentent le hammâm en même temps que des femmes associationnistes

116. Ibn Habîb, op. cit., 234 ; Muttaqî, op. cit., 245, n 27423.

117. Ibn Abî Shayba, op. cit., 104, $\mathrm{n}^{\circ} 1179$. Le transmetteur de cette tradition est Makhûl, juriste syrien.

118. C'est dans cette sourate que se trouvent les principaux versets coraniques - 24, 30 et 31 - qui ont trait à la police du regard. Voir Benkheira, L'amour de la Loi, p. 56-80.

119. ' Abd al-Razzâq, op. cit., 295, n 133. 
(mushrikât $)^{120}$. Défends-le leur avec fermeté ! Il n'est pas licite à une femme qui croit en Dieu et au Jour dernier que des femmes qui n'appartiennent pas à sa religion portent le regard sur ses parties intimes ${ }^{121}$. Dans une version abrégée, il aurait simplement enjoint à ses destinataires : "Interdisez à leurs femmes de fréquenter en même temps que les vôtres les bains publics ». "Ubâda b. Nusayy (m. 118/736), Makhûl (113/731) et Sulaymân b. Mûsâ (m. 115/733), tous Syriens, s'appuyaient sur son exemple pour désapprouver que des sage-femmes scripturaires assistent des musulmanes dans les

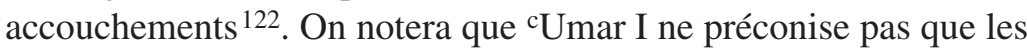
femmes non musulmanes portent des signes distinctifs : cela sera le fait du Calife abbâside al-Muqtadî (m. 487/1 094).

- La politique de ${ }^{\mathrm{c}}$ Umar II (m. 101/720).

Un autre Calife célèbre aurait lui aussi joué un rôle. Il se trouve que c'est un homonyme du premier : 'Umar b. ${ }^{\mathrm{c}} \mathrm{Abd}$ al- ${ }^{\mathrm{c}} \mathrm{Azîz} \mathrm{ou}{ }^{\mathrm{c} U m a r}$ II. Celui-ci aurait donné une instruction similaire à celle de cUmar I au gouverneur de Basra et aux commandants des garnisons (umarấ al-ajnâd), mais sans référence au cas particulier des femmes ${ }^{123}$. Ailleurs on le voit faisant donner la bastonnade à un homme qui

120. S'agit-il de chrétiennes?

121. Qurtubî rapporte une version différente de cette missive : « J'ai appris que des femmes tributaires fréquentaient le hammâm en même temps que des musulmanes. Empêche cela... Il n'est pas permis à la tributaire de voir la nudité de la musulmane ». Ibn 'Abbâs était du même avis : " Il n'est pas licite, disait-il, que la chrétienne ou la juive voit la musulmane nue, afin qu'elle ne la décrive pas à son époux ». Cependant, note Qurtubî, cette question est l'objet de divergences entre les juristes musulmans. Car si la mécréante est l'esclave d'une musulmane, il est permis qu'elle porte le regard sur la nudité de sa maitresse, sinon, cela n'est pas permis en raison de la rupture du lien d'amitié entre les musulmans et les mécréants (li-nqitâc al-walâya bayna ahl al-islâm wa ahl alkufr) (op. cit., XI, 155). Voir aussi Tabarî, Jâmic al-bayân fî ta'wîl al-Qur'ân, Beyrouth., 1984, IX, 307, n 25986 ; Râzî, Mafâtih al-ghayb, Beyrouth, s. d., XXIII, 207.

122. 'Abd al-Razzâq, op. cit., 296, n 1136 ; Ibn Hanbal, Ahkâm al-nisâ', éd. Sulaym, Beyrouth, 2002, 39-40, n 36, 37, 38 ; Tabarî, op. cit., $\mathrm{n}^{\circ} 25985$; Qurtubî, op. cit., XI, 155 ; Ibn al-Qayyim al-Jawziyya, Ahkâm ahl al-dimma, Beyrouth, 1995, II, 184 ; Ibn al-Qattân, Al-nazar fî ahkâm al-nazar bi-hâssati al-basar, éd. Samadî, Beyrouth/Casablanca, 1996, 233, $\mathrm{n}^{\circ} 54$.

123. Ibn Abî Shayba, op. cit., 104, $\mathrm{n}^{\circ} 1176$; al-Mallâ', Al-kitâb al-jâmic li-sîrat ${ }^{c}$ Umar b. ${ }^{c} A b d$ al- ${ }^{c} A z \hat{\imath} z$, éd. Ghazzî, Beyrouth, 1996, I, 153, n 15. 
était entré sans pagne dans un bain et au propriétaire du bain, pour n'avoir pas fait respecter la loi ${ }^{124}$. Selon le traditionniste qui a compilé le recueil des traditions que ce célèbre Calife aurait transmises, après qu'on lui aurait rapporté un hadîth qui interdit le hammâm aux femmes, il aurait décidé de le mettre en application après avoir demandé à Abû Bakr b. ${ }^{\mathrm{c}} \mathrm{Amr}$ b. Hazm d'en vérifier l'authenticité auprès de Muhammad $b$. Tâbit qui en était le transmetteur. C'est ainsi qu'il aurait ordonné à son Administration d'interdire l'accès des thermes aux femmes ${ }^{125}$. Il est également présenté comme ayant été relativement hostile à la mixité religieuse dans les bains publics. On relèvera deux différences notables avec la politique de son prédécesseur. D'une part, son intérêt ne se limite pas au seul cas des femmes. D'autre part, il ne cherche pas à interdire totalement aux non musulmans la fréquentation des bains publics en même temps que les musulmans. Il aurait ordonné à ses représentants en Syrie-Palestine d'interdire notamment aux Juifs et aux Chrétiens de se rendre au bain le vendredi tant que la prière collective n'était pas achevée ${ }^{126}$. Ses motivations semblent ainsi totalement différentes de celles de 'Umar I. Ce qui préoccupait ce dernier, c'était la préservation de l'honneur des musulmanes: les non musulmanes étant non seulement des étrangères mais par principe supposées hostiles aux musulmanes, il valait mieux éviter qu'elles ne voient ces dernières nues. Elles pouvaient nuire à leur réputation en décrivant leurs charmes ou en les raillant. Les raisons de la décision de 'Umar II semblent complètement différentes. Il ne s'agit plus seulement des femmes, et il n'est plus question d'honneur. Comme

124. Ibn Abî Shayba, op. cit., n ${ }^{\circ} 1181$ et 1182 ; Ibn Sacd, Kitâb altabâqât al-kubrâ, Beyrouth, s.d., V, 263.

125. Ibn $\mathrm{Sa}^{\mathrm{c}} \mathrm{d}$, op. cit., 263 ; Bâghindî, Musnad ${ }^{c} U m a r ~ b . ~{ }^{c} A b d$ al-cAzîz, éd. Muhammad 'Awwâma, Damas/Beyrouth, 1987, 181-3 ; Bayhaqî, op. cit., 157 ; Hâkim, op. cit., 322, $\mathrm{n}^{\circ} 7783$; Ibn al-Jawzî, Ahkâm al-nisâ', éd. Muhammad al-Iskandrânî, Beyrouth, 2003, 31 ; Ibn Hajar al-Haytamî, op. cit., 278.

126. Ibn al-Qayyim, op. cit., 170. On prête à 'Umar b. ${ }^{c} A b d$ al-cAzîz de nombreuses décisions hostiles aux membres des autres communautés religieuses (voir Mohammed H. Benkheira, 2004 : « Les non musulmans et le Haram » in Alain Le Boulluec, ed., A la recherche des villes saintes, Brepols, coll. Bibliothèque de l'Ecole des Hautes Etudes, Sciences Religieuses, 2004, 15-32). 
la défense concerne seulement le vendredi, il faut la mettre en rapport avec le bain que le fidèle doit prendre ce jour-là pour participer à la prière collective. Il s'agit probablement, à cette occasion exceptionnelle, d'éviter l'engorgement des bains et de donner la priorité aux musulmans. Ce serait donc a priori une décision qui n'aurait pas un caractère intrinsèquement religieux.

- La politique califale au $\mathrm{V}^{\mathrm{e}} / \mathrm{XI}^{\mathrm{e}}$ siècle.

Le Calife fâtimide al-Hâkim impose en 399/1 009 aux chrétiens de porter au cou une croix et aux juifs une clochette. Les chroniqueurs signalent que le Calife abbâside a agi lui aussi dans le même sens. En 484/1091, la question de la mixité religieuse dans les bains publics revient sur le tapis à Baghdâd. Un rescrit du Calife al-Muqtadî (m. 487/1 094) impose aux femmes scripturaires de porter plusieurs signes distinctifs quand elles vont au bain afin d'être reconnues ${ }^{127}$. Le règne de ce Calife est émaillé de troubles et de conflits liés à la place et au statut des tributaires $(\underline{\operatorname{dimm}} \hat{\imath})^{128}$.

\section{Les hommes de religion}

Même s'ils n'ont le monopole de l'autorité religieuse qu'à certaines époques, le rôle joué par les hommes de religion n'est pas négligeable. Ils sont profondément divisés au sujet du hammâm. Les deux grands courants qui traversent ce corps sont d'une part ceux qui le rejettent et refusent de le fréquenter, d'autre part ceux qui s'y rendent et préconisent de le moraliser. C'est cette dernière tendance, dont les

127. Ibn al-Jawzî, Al-Muntazam, éd. ${ }^{c}$ Atâ, Beyrouth, 1992, XV, 292. Voir Râficî, Al-c'Azîz sharh al-wajîz, Beyrouth, 1997, XI, 542-4, qui discute longuement la nature et la forme des signes distinctifs ainsi que le statut de la mixité religieuse dans les bains publics; Nawawî, Rawdhat al-tâlibîn, éd. 'Abd alMawjûd et Mucawwad, Beyrouth, 1992, VII, 514.

128. Le ve siècle de l'Hégire est marqué par un mouvement de « restauration » sunnite, qui finit par l'emporter sur les imâmites au sein même du Califat abbâside et sur les ismaéliens, à l'extérieur, en aidant à la chute des Fâtimides en Égypte (voir à ce sujet Georges Makdisi, Ibn ${ }^{c}$ Aqîl et la résurgence de l'Islam traditionnaliste au XI siècle, Damas : IFEAD, 1963, 153-62 et "The sunnî revival" (1973), in History and Politics in Eleventh-Century Baghdad, Londres, Variorum Reprints, $\mathrm{n}^{\circ}$ VI, 1990). 
conceptions coïncident avec la conception défendue par les autorités politiques - comme on vient de le voir - qui finira par l'emporter.

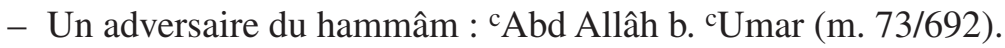

Parmi les autorités religieuses, qui sont très critiques à l'égard de la fréquentation du hammâm, on note la présence du fils de cUmar I, ${ }^{c}$ Abd Allâh b. ${ }^{c}$ Umar (m. 73/692). Ce dernier est associé à de nombreuses traditions en relation directe ou indirecte avec le hammâm et surtout le problème de la nudité. Au dire de son affranchi, Nâfic (m. entre 117 et 120/735-38) ${ }^{129}$, il ne fréquentait pas le bain et ne s'épilait pas non plus ${ }^{130}$. Cependant, d'autres fois, il est représenté, toujours selon son affranchi, recourant à la pâte à épiler pour se débarrasser de ses poils. Dans un récit, ce dernier rapporte : «J'étalais la pâte à épiler sur son corps alors qu'il était chez lui et portait un pagne (izâr). Quand je terminais, je sortais ; et il s'occupait lui-même de la partie de son corps qui était couverte par le vêtement ». Une autre tradition vient contredire ce récit. Le récit, sous une forme indirecte, est dû également à Nâfic : "Ibn 'Umar n'usa de pâte à épiler (nûra) qu'une seule fois. Il m'a demandé à moi et à un autre de ses affranchis de l'y aider ». Le même transmetteur rapporte qu'Ibn cUmar n'allait pas au hammâm dans ce but, mais y procédait dans son domicile. Selon un autre récit, au contraire, c'est le patron même du hammâm qui lui appliquait la pâte à épiler ${ }^{131}$. Ailleurs on le représente recevant un visiteur alors qu'une de ses esclaves est en train de l'épiler. Comme pour se justifier, il dit : «La pâte à épiler affine la peau ${ }^{132}$. Quand il se rasait la tête, probablement lors des cérémonies finales du pèlerinage, il arrosait son crâne d'un parfum à base de safran $(\underline{h} a l \hat{u} q)$. Un jour, en public, il demanda au barbier qui venait de le raser, de le débarrasser également des poils de la poitrine qui l'incommodaient ${ }^{133}$. Il avait en horreur le spectacle des corps nus des hommes à l'intérieur du hammâm. Afin d'expliquer son hostilité au bain public, on rapporte le récit suivant, d'après Nâfic :

129. Au sujet de ce personnage, voir Juynboll, op. cit., $\mathrm{n}^{\circ}$ IX, qui voit en lui un personnage fictif.

130. ' Abd al-Razzâq, op. cit., 292, n 1124.

131. Ibn Sacd, op. cit., IV, 153.

132. Ibn $\mathrm{Sa}^{\mathrm{c}} \mathrm{d}$, op. cit., 154.

133. Ibn $\mathrm{Sa}^{\mathrm{c} d}$, op. cit., 155. 
Il s'y rendit un jour et revêtit un pagne. Quand il fut à l'intérieur de la salle chaude, il vit des gens nus. Il détourna ses yeux en direction du mur ${ }^{134}$ et dit [à son serviteur] :

« Ô Nâfic ! apporte-moi mes vêtements ! ». Je les lui ai apportés ; il s'en enveloppa, couvrant y compris sa tête ; il me donna ensuite la main afin que je le guide, jusqu'à ce qu'il fût dehors. Il ne remit plus jamais les pieds dans un hammâm. ${ }^{135}$

Il existe une autre version de ce récit, due à un autre transmetteur :

J'ai accompagné un jour Ibn 'Umar au hammâm. Une fois à l'intérieur, nous nous sommes enveloppés dans des pagnes. Je suis entré dans la première salle et il me suivit. J'ouvris la seconde porte et lui me suivait toujours. Quand j'ouvris la troisième porte, il vit des hommes tout nus. Il mit aussitôt sa main sur les yeux et dit : Louange à Dieu ! voici une chose grave et hideuse, qui a lieu en islâm. Il ressortit aussitôt et informa le tenancier du bain. Ce dernier chassa les individus incriminés et lava le hammâm ${ }^{136}$. Ensuite il envoya dire à Ibn ' ${ }^{\mathrm{C}} \mathrm{Umar}$ : Ô Abû cAbd al-Rahmân! il n'y a plus âme qui vive à l'intérieur du hammâm. Alors ce dernier revint, et je l'accompagnai. J'entrai le premier, tandis qu'il venait à ma suite, jusqu'à la troisième salle. Quand il toucha l'eau, il constata qu'elle était brûlante : [Voici] la pire des demeures, qui a été débarrassée de toute pudeur, dit-il, mais la plus agréable aussi, où celui qui le veut s'y remémore [le Feu éternel] ${ }^{137}$.

La dernière phrase est particulièrement importante : ce thème sera ensuite constamment associé au hammâm (voir plus bas). S'il n'est pas sûr qu'on puisse en faire remonter les origines jusqu'à Ibn 'Umar, il paraît évident qu'on peut en dater l'apparition à l'époque d'Ibn $\mathrm{Sa}^{\mathrm{c}} \mathrm{d}$ (m. 230/845), qui a colligé cette tradition, voire même plus tôt puisqu'une expression assez semblable se retrouve dans la compilation de Ibn Abî Shayba ${ }^{138}$. Les transmetteurs directs du compilateur sont Wakî̀ (m. 192/812) et Jarîr b. ${ }^{\mathrm{c}}$ Abd al-Hamîd (m. 188/804). Le second était juge à Ray, en Perse, mais il se forma à Kûfa. Jarîr, qui a une assez bonne réputation comme transmetteur, semble avoir été un sunnite original. En effet, alors qu'il critique de

134. C'est une attitude que vont cultiver les hommes de religion zélés comme, par exemple, Hâlid b. Macdân : selon Baghawî (m. 510/1117), quand il allait au bain, il se mettait à l'écart des autres baigneurs et tournait la tête vers le mur (op. cit., 125).

135. 'Abd al-Razzâq, op. cit., $\mathrm{n}^{\circ} 1125$.

136. Il s'agit de la salle chaude.

137. Ibn $\mathrm{Sa}^{\mathrm{c}} \mathrm{d}$, op. cit., 153-4.

138. Op. cit., $103, \mathrm{n}^{\circ} 1170$ et $104, \mathrm{n}^{\circ} 1173$. 
vieilles autorités pour leurs positions - Ibn Abî Najîh parce qu'il était partisan du libre-arbitre (qadar) et Ibn Jurayj parce qu'il était partisan du mariage temporaire $\left(m u t^{c} a\right)$ qui est rejeté par les sunnites mais non par les chiites -, qu'il était d'une grande piété - on le présente comme pratiquant les veillées nocturnes (sâhib layl) et il est rangé parmi les dévots d'un abord difficile ( $\min$ al-cubbâd al-

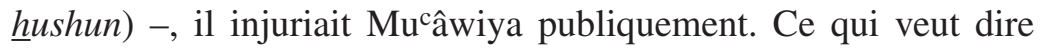
qu'il était pro-alide. ${ }^{139}$

Dans cette seconde version, Ibn 'Umar apparaît moins intransigeant.

On rapporte également un récit différent pour rendre compte de son attitude : on lui conseilla une fois alors qu'il était malade de se rendre au hammâm. Quand il entra dans la salle chaude, vêtu d'un pagne, le spectacle des hommes le pénis en l'air (fa-idâ huwa bi-gharâmîl) le choqua tellement qu'il rebroussa le chemin immédiatement. Il s'écria : «Sortez-moi d'ici! » ${ }^{140}$. Une autre fois, on le rencontre pendant le pèlerinage, à Minâ. Après lui avoir rasé la tête, le barbier s'occupe de ses bras. Quand il se rendit compte que les gens étaient en train de l'observer, il dit : Ceci n'est pas une règle (sunna), mais je ne fréquente pas le hammâm. Alors un homme lui demanda : Qu'est-ce qui t'empêche de t'y rendre ô Abû cAbd al-Rahmân ? - Je déteste que l'on me voit nu. - Il te suffit pour cela de porter un pagne. - Je déteste aussi voir les autres nus. » Dans une autre version de ce récit, après s'être rasé le crâne, il ordonne au phlébomiste de lui raser la nuque. Comme les gens s'agglutinent autour de lui pour le regarder, il leur crie : Ceci n'est pas une obligation (sunna), mais j' ai cessé de fréquenter le bain parce qu'il fait partie des raffinements de l'existence ( $\min$ raqî́q al-caysh)». ${ }^{141}$

Selon une tradition, son fils Sâlim b. ${ }^{\mathrm{c} A b d}$ Allâh b. ${ }^{\mathrm{c}}$ Umar (m. 106/725) s'épilait aussi, mais on ne connaît pas son opinion au sujet de la fréquentation du hammâm ${ }^{142}$.

139. Ibn Hajar, op. cit., I, 297-8. Plusieurs sunnites du II $/ \mathrm{VIII}^{\mathrm{e}}$ siècle, membres du groupe informel des ahl al-hadit, sont parfois présentés comme ayant des sympathies pro-chiites. C'est par exemple le cas de Wakîc b. al-Jarrâh (m. 192/812), de Mansûr b. al-Muctamir (m. 132/749) et de ${ }^{\mathrm{c}} \mathrm{Abd}$ al-Razzâq (m. 211/826), une de nos principales sources ici. Ce sera aussi le cas, plus tard, du célèbre traditionniste Nasâ'î (m. 303/915), l'auteur d'une des six collections sunnites dites « canoniques ».

140. Ibn $\mathrm{Sa}^{\mathrm{c}}$, op. cit., 154.

141. Ibn $\mathrm{Sa}^{\mathrm{c} d}$, op . cit., 154 et 155. Voir aussi ${ }^{\mathrm{c}} \mathrm{Abd}$ al-Razzâq, op. cit., 192, $\mathrm{n}^{\circ} 1126$.

142. Ibn Abî Shayba, op. cit., 105, nº 1189. 
- Les partisans du hammâm

L'insistance sur le port du pagne et sur la nécessité de se couvrir les parties en général est un leitmotiv du discours des oulémas dès une époque très ancienne. Ils ne remettent pas en question la fréquentation du hammâm mais réclament le respect du port du pagne. C'était le point de vue de Sacîd b. Jubayr (m. 95/714), juriste de Kûfa, qui déclarait illicite d'entrer au hammâm sans pagne ${ }^{143}$. cAmr b. Maymûn disait: "Quand l'un de vous entre dans le hammâm ou dans l'Euphrate ${ }^{144}$, qu'il se couvre avec un pagne ou mette des habits (tiyab) $»^{145}$. Toutefois, certains amateurs du hammâm ignoraient les règles de la pudeur promues par les autorités religieuses. Abû Ja'far, qui ne rentrait au hammâm qu'enveloppé dans un pagne qui le couvrait jusqu'aux genoux, ne l'en détestait pas moins car de nombreux hommes n'en portaient pas et circulaient totalement nus ${ }^{146}$. Un témoin rapporte : «On a interrogé un jour Hasan al-Basrî (m. 110/728) à propos de la fréquentation du hammâm (duhûl al-hammâm) : - Il n'y a aucun mal si l'on porte un pagne. - Mais on y rencontre des gens nus ( $\left.{ }^{c} u r a ̂ t\right)$. - L'islâm est plus fort que cela ${ }^{147}$. Le fameux Ibrâhîm Nahacî̂ (m. 96/175), juriste de Kûfa, disait : "On peut saluer [les gens dans le hammâm], s'ils sont vêtus d'un pagne (izâr), dans le cas contraire, on ne les saluera pas ${ }^{148}$. Les hommes de religion les plus pieux sont très scrupuleux à ce sujet comme le montre l'exemple suivant. Un jour, Shacbî (m. 103/721) qui était au hammâm, tardait à se laver les pieds ; quand un de ses voisins l'interrogea à ce sujet, il répondit : «Un homme est en train de m'observer ${ }^{149}$, montrant ainsi son souci de ne pas se découvrir.

143. ' Abd al-Razzâq, op. cit., I, 290, nº 1 118. Cf. aussi Ibn Abî Shayba, op. cit., $\mathrm{n}^{\circ} 1177$.

144. Ce qui signifie que l'on pouvait se laver dans le fleuve.

145. Ibn Abî Shayba, op. cit., $\mathrm{n}^{\circ} 1180$.

146. Ibn Abî Shayba, op. cit., $\mathrm{n}^{\circ} 1178$.

147. ' ${ }^{\mathrm{A}}$ Abd al-Razzâq, op. cit., 292, $\mathrm{n}^{\circ} 1123$.

148. Ibn Hajar/Buhârî, Fath al-bârî sharh Sahîh al-Buhâhrî, Damas-Riyâd, 1997, I, 375.

149. Ibn Abî Shayba, op. cit., 102, n 1153 ; Ibn Hanbal, Al-jâmic fì alcilal wa macrifat al-rijâl, éd. Baydûnî, 1990, I, 286, nº 2090. 
Une des raisons pour lesquelles le hammâm a été adopté par les musulmans et accepté par la majeure partie des oulémas est que l'on s'y épile, notamment le pubis ${ }^{150}$. Beaucoup d'hommes de religion s'y rendaient à cette fin. Selon une tradition, Muhammad s'épilait lui-même le bas-ventre [sous-entendu : il ne permettait pas à autrui de faire cela] ${ }^{151}$. Mais selon une autre tradition, ni lui ni les deux premiers califes n'ont sacrifié à cet usage ${ }^{152}$. Hasan al-Basrî ne s'épilait pas non plus ${ }^{153}$. 'Umar I était poilu et se rasait ; quand on lui parla de la pâte à épiler (nûra), il rejeta le procédé en le qualifiant de «délice mondain » $\left(n a^{c} \hat{\imath} m\right){ }^{154}$. Un jour, ${ }^{\mathrm{c}} \mathrm{Amr}$ b. Dînar (m. 125/742) accompagne Abû al-Sha'tâ'. A l'aide d'un onguent, il l'épile, mais quand il introduit la main entre ses cuisses, l'autre refuse en protestant : il s'occupe alors lui-même de ses parties intimes ${ }^{155}$. Quant à Jâbir b. Zayd (m. 103/722), traditionniste et juriste ibâdhite de Basra, il n'y voyait aucun mal ${ }^{156}$. Le Yéménite Tâwûs (m. 106/ 724) ${ }^{157}$, auquel on attribue des propos hostiles au hammâm, ainsi que les Mecquois 'Atâ'b. Abî Rabâh (m. 114/732) et Mujâhid b. Jabr (m. 104/722) avaient l'habitude de fréquenter le hammâm, où ils s'épilaient ${ }^{158}$. Ibn Jurayj (m. 150/767) a questionné à ce sujet son maître Atâ' b. Abî Rabâh : «-T'es-tu déjà épilé dans le hammâm? - Oui, une fois ${ }^{159}$.

150. L'épilation ne concerne pas seulement le pubis et les aisselles, mais, pour les femmes, l'ensemble du corps, ainsi qu'en atteste cette tradition au sujet de Salomon et de la reine de Saba, qui était une femme velue. Salomon dit : - Qu'est-ce qui fait disparaître cela ? - La pâte à épiler (nûra). C'est ainsi que l'on fabriqua cette pâte qui devait servir à épiler (Ibn Abî Shayba, op. cit., $\left.105, \mathrm{n}^{\circ} 1187\right)$.

151. ' Abd al-Razzâq, op. cit., 292, n 1128 ; Ibn Abî Shayba, op. cit., $\mathrm{n}^{\circ} 1191$; Ibn Hanbal, cIlal, I, 292, n 2147 ; Ibn Muflih, Al-âdâb al-shar‘iyya, éd. Arnâ'ût et Qayyâm, Beyrouth, 1996, III, 321.

152. Ibn Abî Shayba, op. cit., $\mathrm{n}^{\circ} 1186$.

153. Ibn Abî Shayba, op. cit., $\mathrm{n}^{\circ} 1188$.

154. Ibn Abî Shayba, op. cit., nº 1192.

155. ' Abd al-Razzâq, op. cit., 292-3, n 1129.

156. Ibn Abî Shayba, op. cit., $\mathrm{n}^{\circ} 1190$.

157. Ce dernier est le transmetteur d'un hadith $\operatorname{marf} \hat{u}^{c}$ : "Que celui d'entre vous qui entre au hammâm se couvre » (Ibn Abî Shayba, op. cit., n 1 184).

158. Ibn Abî Shayba, op. cit., $\mathrm{n}^{\circ} 1185$.

159. ' Abd al-Razzâq, op. cit., 293, nº 1129. 
L'épilation était parfois la principale raison pour laquelle on fréquentait le hammâm, comme le montre l'anecdote suivante. Abû Tâhir b. 'Abd Allâh al-Asbârî (m. 276/889) est allé un jour au bain, alors qu'il n'y avait pas âme qui vive, pour s'épiler (li-yatanawwara); un homme l'y rejoignit. Cela l'affligea considérablement, car il souhaitait demeurer seul. Quand il quitta le bain, il fit une prière à Dieu : «Ô Seigneur! implora-t-il. Fais que je n'ai plus besoin de me rendre au bain !» Sa prière fut exaucée : plus aucun poil ne poussa sur son corps ${ }^{160}$. Cette anecdote ne relève pas totalement du genre hagiographique. Mettons de côté le miracle, que reste-t-il ? Nous sommes face à un ascète qui ne fréquente le bain public que dans le but de s'épiler, c'est-à-dire pour observer une prescription religieuse, car l'épilation des aisselles et du pubis fait partie des règles de « la religion première » (fitra). Mais il est contraint de fuir le hammâm à cause de la promiscuité qui y règne.

La peur de l'homosexualité n'est pas étrangère à la campagne de moralisation et de répression du comportement des baigneurs. C'est ce dont témoigne l'anecdote suivante, qui met en scène une des figures les plus prestigieuses $\mathrm{du} \mathrm{II}^{\mathrm{e}} / \mathrm{VIII}{ }^{\mathrm{e}}$ siècle. Un jour que Sufyân Tawrî (m. 161/777) était au hammâm, un jeune garçon, au beau visage, pénétra. Sufyân s'écria : « Ôtez-le de ma vue ! » On fit sortir le bel enfant. Le grand juriste de Kûfa expliqua : "Si chaque femme est accompagnée d'un démon, chaque jeune garçon l'est par dix démons! »161. Dans un traité contre l'homosexualité, le shâficite Shams al-dîn Muhammad b. 'Umar al-Ghumarî (m. 849/1445), originaire de la ville de Wâsit, écrit : "Quant à la fréquentation du hammâm par les garçons [impubères] (sibyân) ensemble, on peut la comparer à la fréquentation du hammâm aussi bien par les femmes que par les hommes, [en concluant] qu'elle est permise. Mais il est primordial d'éviter qu'ils se mélangent (wa-l-awla ${ }^{c}$ adam ihtilâtihim) [avec les mâles adultes] par crainte de la débauche $($ fasâd $) \gg .{ }^{162}$ On

160. Samcânî, Al-ansâb, Beyrouth, 1988, I, 126-7.

161. Dahabî, Al-kabâ'ir, Beyrouth, s.d., p. 58. Il y a là une référence explicite au débat sur l'éphèbe (al-amrad).

162. Al-hukm al-madhbût fì tahrîm ficl qawm lût, Tantâ, 1988, 54. Je remercie mon ami Avner Giladi de l'Université de Haïfa qui m'a aimablement procuré une copie de cet ouvrage. 
doit donc surtout éviter qu'ils aillent au bain aux mêmes heures que les hommes : c'est pour cela que dans la pratique ils y vont en même temps que les femmes, étant donné qu'il n'y a pas d'heures qui leur soient réservées en propre.

(À suivre)

hocine.benkheira@gsrl.cnrs.fr 